\title{
Critical Evaluation of a Survey Claiming "Long-Term Adverse Outcomes from Neonatal Circumcision"*
}

\author{
Stefan A. Bailis ${ }^{1}$, Stephen Moreton ${ }^{2}$, Brian J. Morris ${ }^{3}$ \\ ${ }^{1}$ Cornerstone Therapy \& Recovery Center, St. Paul, USA \\ ${ }^{2}$ CircFacts, Warrington, UK \\ ${ }^{2}$ School of Medical Sciences and Bosch Institute, University of Sydney, Sydney, Australia \\ Email: brian.morris@sydney.edu.au
}

How to cite this paper: Bailis, S.A., Moreton, S. and Morris, B.J. (2019) Critical Evaluation of a Survey Claiming "Long-Term Adverse Outcomes from Neonatal Circumcision". Advances in Sexual Medicine, 9, 67-109. https://doi.org/10.4236/asm.2019.94006

Received: July 26, 2019

Accepted: September 14, 2019

Published: September 17, 2019

Copyright $\odot 2019$ by author(s) and Scientific Research Publishing Inc. This work is licensed under the Creative Commons Attribution International License (CC BY 4.0).

http://creativecommons.org/licenses/by/4.0/

\section{(c) (i) Open Access}

\begin{abstract}
We critically evaluate an online "Global survey of circumcision harm" that gauged beliefs of men who thought that their neonatal circumcision had harmed them. Sequential evaluation of the survey data and claims reveal numerous serious flaws that are at odds with strong scientific evidence. Moreover, the one-sided study design and "loaded" survey title meant the findings were not representative of the general population of circumcised males. None of the participants' claimed physical problems were confirmed by a health practitioner. Belief in this seriously flawed survey has potential to cause psychological harm to vulnerable men influenced by anti-circumcision claims, and as such has serious detrimental implications for male sexual health. The survey appears driven less by empiricism and more by psychological forces, as we show in detail. The overwhelming body of high quality medical scientific evidence finds no adverse effect of male circumcision on sexual function and pleasure, but strong evidence for a wide array of lifetime benefits in protection against infections, dermatological problems, and genital cancers. Consistent with the United Nations Convention on the Rights of the Child, children are entitled to low risk procedures that are beneficial to their health. In conclusion, the survey and its uncritical presentation do a disservice to evidence-based medicine, sexual health, mental health, public health, human rights, and pediatric policy development. It should therefore be dismissed as unreliable.
\end{abstract}

\section{Keywords}

Sexual Function, Psychology, Male Health, Anti-Circumcision

*The views expressed herein do not necessarily reflect those of Cornerstone Therapy \& Recovery Center. 


\section{Introduction}

Circumcision of boys is a procedure that has been performed for thousands of years by a diversity of cultures worldwide [1]. In Europe there is evidence for MC in the Paleolithic era [2]. Although male circumcision (MC) is commonly performed for cultural or religious reasons, in recent times health reasons have increasingly come to the fore as a reason for MC. Data on MC prevalence in every country and territory led to an estimate of $38 \%$ - 39\% for global MC prevalence [3] [4]. Prevention of foreskin inflammation and sexual problems stemming from phimosis may explain why diverse societies worldwide implemented $\mathrm{MC}$ in ancient times, with the practice then becoming a common cultural or religious custom [1]. Its implementation in patriarchal societies would unlikely have occurred if MC had a detrimental effect on penile function or sexual pleasure. In fact, MC, by elimination of the sexual impediment of phimosis, allowed cultures to control the start of a male's reproductive life [1] [5].

In Anglophone countries, the procedure generally takes place early in infancy. The most recent US Centers for Disease Control and Prevention (CDC) survey of males aged 14 - 59 years found a rising trend in MC prevalence, reaching 91\% in whites, $76 \%$ in Afro-American blacks, and $44 \%$ in Hispanic peoples [6]. Detailed reviews by the American Academy of Pediatrics (AAP) [7] [8] and the CDC [9] concluded that benefits exceed risks. A study by CDC researchers in 2014 of 1.4 million circumcisions found an adverse event frequency of $0.4 \%$ for neonatal MC (NMC) [10]. The AAP infant MC policy in 2012 reached similar conclusions based on earlier data, and also noted that prevalence of serious complications requiring hospital admission was only $0.02 \%$ [8]. The CDC review stated that benefits exceed risks by "100:1" [9].

In contradistinction to strong scientific evidence, and perhaps because of it, fringe groups have emerged in recent years claiming that MC, particularly NMC, has adverse consequences for sexual health. Most claims have been based on anecdotes or low-quality surveys. An extensive systematic review has recently evaluated the claims by MC opponents and found them to be based on speculation or misinformation [11].

We were therefore interested in assessing whether a survey involving 1008 mostly US men circumcised in infancy [12] might provide data able to shed light on the claim by MC opponents that NMC adversely affects a man's sexual function. The study, by Hammond and Carmack (hereafter H\&C), involved an online survey that attempted to identify factors contributing to concerns of men who were unhappy with having been circumcised. The lead author, Timothy Hammond, self-proclaimed founder of the National Organization to Halt the Abuse and Routine Mutilation of Males (NOHARMM) and the National Organization of Restoring Men (NORM), has also produced an online video in which he presents the findings [13]. A preliminary version of this survey [14] was used by Hammond in 2013 in an attempt to influence the Canadian Pediatric Society [15]. As the more recent survey by $\mathrm{H} \& \mathrm{C}$ is one of the more influential and 
widely publicised anti-MC works, a detailed examination of its litany of claims is merited.

The present paper evaluates the survey's findings and the extensive arguments used by H\&C to support them. We do so sequentially, following H\&C's main section headings so the reader can refer to the article and then read our criticisms chronologically. The literature we cite drew on extensive collections by the authors of over 5000 papers on MC retrieved from weekly PubMed alerts, bibliography searches of these, and other sources.

\section{Arguments Made: Are They Valid?}

\subsection{Appeal to History, Legality and Ethics}

H\&C's article starts by devoting 7 pages to making a case against MC, especially when performed in childhood. It then presents the methods used and results, before spending 6 pages discussing and speculating about the meaning of the findings. Being an online survey, it was prone to selection bias by attracting a subset of men who wanted to vent, whereas well-adjusted men with no such grievances might have decided not to waste their time doing the survey.

In their Introduction, the authors of the study correctly start by stating that MC involves removal of part or all of the "penile prepucelforeskin", but they fail to state that the tissue removed can be either "healthy" or diseased. They then cherry-pick a few historical anecdotes from the $19^{\text {th }}$ century claiming "anti-sexual effects" were used to support MC, but they do not refer to the more widely acknowledged benefits of MC espoused in Victorian times, such as protection against syphilis [16], other STIs [17], phimosis [17] [18], paraphimosis [17], balanitis [17], preputial adhesions [18], inferior hygiene [17], and cancer [19]. These benefits appeared in early $20^{\text {th }}$ century publications as well [20] [21] [22]. The publication by Silby, railing against masturbation, made no mention of $\mathrm{MC}$ for prevention [22], thus undermining claims by MC opponents that a major reason for MC in Victorian times was to prevent masturbation. H\&C mention that more than a million boys in the US are circumcised annually. When they refer to the anti-MC movement, that they are a part of, the number of members is not stated, perhaps because the number is low. The intention stated by $\mathrm{H} \& \mathrm{C}$ at the end of the Introduction is to address a "recent ethical discourse defending the child's human right to bodily integrity", which is a core feature of the anti-MC agenda, and that has been intensively evaluated and dismissed, as we will show.

In H\&C's Background section they invoke legal and ethical arguments opposing MC. They cite publications by anti-MC activists, then a supposed quote from the 1997 World Congress on Sexology using a citation that is actually by the Kinsey Institute. The quote and the citation do not mention MC. They then cite the anti-MC organization Attorneys for the Rights of the Child (ARC). ARC's legal and human rights claims, including reference to United Nations (UN) statements on the rights of the child, have been extensively evaluated by profes- 
sors of law, bioethics, urology, medicine and medical sciences and were found to contradict the ARC's conclusions [23] [24].

Next, H\&C purport to quote a statement by the UN. But what they actually cite is a Table from the ARC website, closer scrutiny of which reveals no mention of MC by the UN in any of its documents. H\&C then refer to the International NGO (non-government organization) Council on Violence against Children (ICVAC) [25]. This 48-page document devotes only a page to MC (from end of page 21 through page 22), noting the WHO's support for its benefit in protection against HIV, but it then quotes from the Royal Dutch Medical Association (KNMG) policy declaring MC can be delayed until the boy is old enough to give consent [26]. The Dutch policy was developed by Gert van Dijk, an ethicist, and lacks an evidence-based review of the scientific evidence. The ICVAC also cites outdated reports in Kenya, Norway and Germany that have failed to translate into legislation, if anything the reverse (see below). The ICVAC ignores the extensive wide-ranging medical benefits of MC that start from the first year of life, as will be enunciated below.

$\mathrm{H} \& \mathrm{C}$ misconstrue a decision by the regional Court in Cologne, Germany, involving a Muslim boy who experienced some bleeding after being circumcised by a doctor [27]. The court in fact found the illegality of circumcision is among the, "...undecided questions of law...", concluding that the defendant was not guilty of a criminal act (see [28] for full English translation). The decision was misinterpreted by news media and $\mathrm{MC}$ opponents as Germany having imposed a ban on MC. In response to the Cologne decision, the German Parliament (The Bundestag) enacted legislation upholding the legal right of parents to choose MC for their sons by a trained professional in a safe environment [29] [30]. The wording suggested that any new law upholding MC in Germany would extend beyond religious reasons.

$\mathrm{H} \& \mathrm{C}$ then misleadingly state that a British judge ruled "that circumcision of boys is 'significant harm' and more damaging than certain minor forms of female genital mutilation" [31]. However, items 72 and 73 of the judgement in this female genital mutilation (FGM) case recognized substantial health benefits of boyhood circumcision that differentiated it from FGM. H\&C follow this anecdote with: "The alleged harmfulness of circumcision is one reason it can be seen as conflicting with a child's rights to health, bodily integrity and future autonomy." It seems ironic that "right to health" appears in their statement when the scientific evidence shows a wide-array of medical and health benefits from MC, particularly when performed in early infancy. Risk-benefit analyses have found benefits of early infant MC exceed risks by at least 100 to one, and that over their lifetime approximately half of uncircumcised males will experience an adverse medical condition attributable to their foreskin [32] [33]. The meta-ethical approach of science is primarily utilitarian, seeking to decide which decision will most likely produce the greatest net benefit. Well-informed public health authorities would most likely be persuaded by the evidence in favor of early infant MC. 


\subsection{Disease Prevention versus Right to "Autonomy"}

The medical scientific consensus in support of MC has been especially strong for HIV. Support increased after the completion of 3 large randomized controlled trials (RCTs) that showed MC provided 50\% - 60\% protection against heterosexual HIV transmission to men [34] [35] [36]. The World Health Organization (WHO) and UNAIDS endorsed MC as an additional important intervention to help reduce HIV incidence in epidemic settings [37]. The trial results were also supported by a systematic review [38] and a Cochrane committee meta-analysis [39]. The WHO, UNAIDS, The Presidents Emergency Fund for AIDS Relief (PEPFAR), The Bill \& Melinda Gates Foundation, The World Bank, and other bodies have been assisting in the large-scale rollout of voluntary medical MC (VMMC) programs in 14 countries in sub-Saharan Africa where the HIV epidemic is highest. This has resulted in 18.9 million MC procedures in these high-priority countries [40], therefore helping to reduce infections and save lives [41]. For long-term benefit, convenience and cost-savings infant MC is starting to be rolled out in epidemic settings as well, with the approval of the WHO. The US CDC recommends VMMC for 12 countries [42]. The MC RCTs have also found risk reductions for several other STIs in men [43]. As a result of MC benefits to males, affirmative policy recommendations were developed by the US CDC [9] and by the AAP [7] [8], the latter policy being endorsed by the American College of Obstetricians and Gynecologists.

One must therefore ask, does the right to "bodily integrity and future autonomy" trump the right to preventive health care, and even to life? Given that the WHO MC program for high-HIV settings is likely to avert millions of HIV infections by the end of the century, one has to ask which right comes first?

The ethics of NMC has been debated extensively. Scholarly assessments suggest that circumcision of male minors is ethical [44]-[50]. Given the wide-ranging protection against multiple medical conditions and infections in infancy and childhood, including STIs in boys who become sexually active, some have argued that it would be unethical to leave boys uncircumcised [46] [48], and that Article 24 (3) of the United Nations (UN) on the Rights of the Child (CRC) might be interpreted as mandating NMC, since not circumcising boys has been deemed as prejudicial to their health [48].

$\mathrm{H} \& \mathrm{C}$ cite various surveys in magazines and online facilities in which circumcised men report unhappiness with their status. Data arising from these is subjective and highly prone to selection bias. They cite a $\mathrm{PhD}$ thesis by Jennifer Bossio from Queen's University, Ontario, that used, in part, social media for recruitment, therefore risking bias (see below). We draw the reader's attention to a screenshot of a post on "the WHOLE Network" (an anti-MC website) flagging Bossio's call for participants and inviting MC opponents to participate (see screenshot in reference [51]). Bossio's later data published in peer-reviewed journals [52] [53] were not, however, cited by H\&C. They fail, moreover, to 
mention that the men Bossio studied had to have been in a sexual relationship with another man for a minimum of 3 months (the mean was 4.2 years) [52]. So, as a result of differences in sexual practices by men who have sex with men (MSM), the results for these men should not be implied as being applicable to heterosexual men. Bossio's findings for women's preferences favored the circumcised penis for appearance and sexual activities. In a study using quantitative sensory testing published in the Journal of Urology, that H\&C do not cite, Bossio et al. found "penile sensitivity did not differ across circumcision status for any stimulus type or penile site," concluding "this study challenges past research [by Sorrells et al.; cited in paragraph 2 of subsection 4.1 below] suggesting the foreskin is the most sensitive part of the adult penis" [53]. H\&C refer to Hammond's "preliminary polp" of men who had contacted anti-MC groups. So is hardly an unbiased sample! Instead of providing evidence of harm from MC, $\mathrm{H} \& \mathrm{C}$ then mention several selected opinion pieces, including ones on anti-MC websites.

In contrast to $\mathrm{H} \& \mathrm{C}$, most surveys published in good journals find initially uncircumcised men are almost all happy after having been circumcised (see below). Obviously, men circumcised as infants would not know whether having been left uncircumcised would have made them less, or more, happy. Wondering what they might or might not be missing out on could trigger speculative thoughts and concerns that whatever sexual or other problem they might be experiencing could be "blamed" on their infant MC. Such thoughts may be fuelled by anti-MC propaganda that is particularly rife on the Internet [54].

In discussing the AAP's infant MC policy in 2012 that stated benefits exceed risks [7] [8], H\&C mention that critics accused the AAP of failing "to describe the known anatomy of the penile prepuce nor [did the AAP] discuss in detail the protective and sexual functions that have been attributed to it in the medical literature." But what anatomy is relevant? And what purported functions did the critics have in mind? Most of the former is irrelevant, and the latter speculative. $\mathrm{H} \& \mathrm{C}$ then allude to (alleged) "functions" of the foreskin, but they do not offer a single example. They refer to an out-of-date AAP brochure in 1984 that mentions only two speculative functions-(1) protection against urine and faeces in infants, and protection more generally throughout life, and (2) sub-preputial smegma as having a "protective, lubricating function for the glans." $\mathrm{H} \& \mathrm{C}$ cite published critiques by MC opponents of the AAP policy, but not the repudiation of these by the AAP Task Force [55] and by others [24] [56] [57] [58].

They point out that an independent review by the CDC released for public comment at the end of 2014 [59] [60] came to the same conclusions as the AAP policy. Whereas the AAP policy did not provide a figure for how much benefits exceed risks, the CDC document stated that benefits of infant MC exceed risks by "100:1." This figure, taken from a detailed risk-benefit analysis published in Mayo Clinic Proceedings [61], also appeared in the CDC's final statement in 2018 [62]. The CDC's updated recommendations included a detailed rebuttal of 
the criticisms by MC opponents of the CDC's draft recommendations [62]. Arguments published in journal articles by MC opponents criticizing the CDC's draft policy were also shown to be flawed [23] [63] [64].

\subsection{Adverse Events from MC}

$\mathrm{H} \& \mathrm{C}$ criticize the AAP policy for not knowing the "true" incidence of complications after infant MC. However, the AAP's policy in 2012 preceded a very detailed study by CDC researchers, published in 2014, of 1.4 million circumcisions (93.3\% in neonates), in which combined prevalence of 41 possible adverse events was $0.4 \%$ for infant MC [10]. But for boys aged 1 - 9 years adverse events were 20 times higher, and for males aged $\geq 10$ years adverse events were 10 times higher. Virtually all were minor and easily treated, with complete resolution. Incidence of potentially serious adverse events was only 0.75 per million for stricture, and was 703 per million for repair of incomplete MC. For uncircumcised infants, adverse events prevalence was $0.11 \%$, including a similar prevalence of strictures as seen in circumcised infants. This 2014 study was cited by the CDC in its draft guidelines and final statement. NMC is preferred because it is simple, quick, low risk, less expensive, heals within a week, has a good cosmetic outcome, and is convenient when compared with the barriers posed by MC of older boys and men (Table 1) [65]. Nevertheless, $\mathrm{MC}$ at any age requires a well-trained, competent surgeon, and pain relief using local anesthesia, although sometimes general anesthesia may be preferred for older boys and men. Provider training, access, affordability (including third-party coverage [i.e., by private insurance policies and, for poor families, Medicaid]), as well as unbiassed education of parents were part of the AAP's recommendations [7] [8].

$\mathrm{H} \& \mathrm{C}$ refer to estimates by an MC opponent claiming there are "117" (or "100+") deaths per year from infant MC in the US [66]. These figures have been discredited because they were based on a dubious assumption that the well-known higher infant mortality in males than females is due to infant MC [67]. In reality, countries with very low MC rates had similar, or even higher, male-to-female infant mortality ratios than the USA. A correlation has also been claimed between MC rate in the US and sudden infant death syndrome (SIDS) [68], but correlation does not imply causation. Deaths can occur from uncontrolled bleeding as a result of de novo hemophilia in an infant with no family history. Infant MC-related deaths are exceedingly rare-and occur mostly in circumcisions by traditional or other non-medical practitioners. A retrospective analysis of infants who had a hospital circumcision between 2001 and 2010 found 1 death per 49,166 circumcisions [69]. Earp and co-authors emphasized that "this figure should not be interpreted as causal but correlational" and "may include both undercounting and overcounting." Deaths were mostly in infants with comorbid conditions such as heart disease (odds ratio [OR] 698), pulmonary circulatory disorders (OR 170) coagulopathy (OR 160), or fluid and electrolyte disorders (OR 68) (all $P<0.001$ ). 
Table 1. The advantages of NMC over MC of older boys and men [65].

\begin{tabular}{|c|c|}
\hline NMC & MC of older boys and men \\
\hline $\begin{array}{l}\text { - Is a simple surgical procedure by competent } \\
\text { doctor }\end{array}$ & - More complex \\
\hline - Quick: takes several minutes & - Takes 30 minutes or more \\
\hline - Cost is lower & - Much more expensive and often unaffordable \\
\hline - Low risk of adverse events $(0.4 \%)$, most minor & - Higher risk of adverse events ( $4 \%-8 \%)$ \\
\hline - Any bleeding is minimal and easily stopped & $\begin{array}{l}\text { Bleeding is more common, requiring cautery } \\
\text { or other interventions }\end{array}$ \\
\hline - Sutures not needed & - Sutures or tissue glue are needed \\
\hline $\begin{array}{l}\text { - Convenient since the baby sleeps most of the } \\
\text { day }\end{array}$ & $\begin{array}{l}\text { - Inconvenient owing to need for time off school } \\
\text { or work }\end{array}$ \\
\hline - Local anesthesia used if aged $<2$ months & $\begin{array}{l}\text { - General anesthesia for age } 2 \text { months to age } 9 \\
\text { years. For men local anesthesia may be used, } \\
\text { although general anesthesia is sometimes } \\
\text { preferred by the surgeon }\end{array}$ \\
\hline - Healing is fast ( $1-2$ weeks) & - Healing takes $\geq 6$ weeks \\
\hline - Cosmetic outcome usually good & $\begin{array}{l}\text { - If stitches are used, stitch marks may be visible } \\
\text { permanently }\end{array}$ \\
\hline - No long-term memory of procedure & $\begin{array}{l}\text { Fear posed to the boy or man of undergoing } \\
\text { an operation }\end{array}$ \\
\hline $\begin{array}{l}\text { - Does not disrupt breast-feeding or other } \\
\text { day-to-day activities }\end{array}$ & $\begin{array}{l}\text { - Abstinence from sexual intercourse required } \\
\text { for the } \geq 6 \text {-week healing period }\end{array}$ \\
\hline
\end{tabular}

\subsection{Sexual Function}

$\mathrm{H} \& \mathrm{C}$ claim that the AAP's statement that MC has no adverse effect on sexual function was "not based on data drawn from males circumcised as infants, but primarily on a small selection of studies regarding adult circumcision whose findings were limited by relatively short follow-up periods." The 2-year follow-up referred to applies to RCTs in Uganda [70] and Kenya [71]. Two years is ample time for any loss of putative "foreskin functions" to be noticed. The men in each RCT expressed a high level of satisfaction with their circumcision-with sexual function and pleasure being either the same or better. As for the question of infant MC, which is the most common time for males to be circumcised in Anglophone countries such as the USA, it is not true that no data exist on sexual function and pleasure in such men. All systematic reviews of the topic, one performed by researchers in Australia and the USA [61], others by researchers in China [72] [73], and one by researchers in Denmark (and published in the Danish Medical Journal) [74], found no difference in sexual function between circumcised and uncircumcised men. A large British probability survey of sexual function also found no differences between circumcised and uncircumcised men [75]. Most of the circumcised participants were circumcised in infancy. A cohort study by Brito et al. in the Dominican Republic, of men who underwent VMMC as adults and were followed-up for 24 months, found that $98 \%$ were satisfied with the outcome, $67 \%$ reported enjoying sex more, and $94 \%$ were satisfied or very satisfied with sexual intercourse. Sexual function improved and sex-related 
coital injuries decreased significantly in most men after VMMC. A meta-analysis of all common types of sexual dysfunction in men found that these did not differ between circumcised and uncircumcised men [72]. A meta-analysis of 5 potential sexual dysfunctions found no difference in premature ejaculation and orgasm, but a $28 \%$ greater intravaginal ejaculatory latency time, $58 \%$ lower erectile dysfunction, and $64 \%$ lower pain during intercourse among circumcised men [73]. A systematic review also examined penile sensitivity and sexual satisfaction, finding that these too were no different between circumcised and uncircumcised men [61]. The findings were supported by a systematic review of histological correlates of penile sensitivity [76] that found the foreskin lacks neuroreceptors for sexual pleasure (such neuroreceptors are mostly genital corpuscles), these instead being concentrated in the glans. In contrast, the neuroreceptors in the foreskin comprise those found in skin across the rest of the body and are able to sense touch, heat, cold, and pain.

A YouGov poll found $86 \%$ of men were happy to be circumcised and only $10 \%$ were not [77]. In comparison, $29 \%$ of uncircumcised men wished they were circumcised [77]. The YouGov poll was likely done on a panel of registered users [78], so was less likely to have been influenced by anti-MC organizations mobilizing their members via social media [51], thereby skewing the results.

$\mathrm{H} \& \mathrm{C}$ assert that "The highly erogenous frenulum, often preserved in adult circumcision, is frequently ablated in neonatal circumcision due to the smaller size of the undeveloped penis". Aside from whether or not it is "often preserved in adult circumcision," is there evidence that the frenulum is "highly erogenous"? Schober et al. found the underside of the glans to be the most erogenous area [79]. The study involved 70 circumcised and 11 uncircumcised American men. Thus, most lacked a frenulum. This fits with Halata \& Munger's observation that "genital end bulbs" (the ones to which erogenous sensation is usually attributed) are concentrated "in the corona and near the frenulum" [80]. Note that those authors state "near the frenulum," not in it. In patients with spinal cord injury semen can be collected by using vibratory stimulation, the favoured areas to accomplish this being the glans [81] and frenulum/underside of the glans [82], coinciding with locations where the concentration of genital corpuscles is highest, and is achieved irrespective of the presence of a foreskin [76]. Even though "frenulum" is mentioned, because many of the subjects were circumcised, one might question whether they actually had a frenulum. Given that the underside of the glans, where the frenulum attaches, is a highly erogenous area, even in males without a frenulum, it begs the question, is the frenulum the real source of erogenous sensation in men who claim their frenulum is erogenous? After all, since the frenulum attaches at the erogenous point, stimulation of the frenulum will, inevitably, stimulate the highly erogenous underside of the glans.

$\mathrm{H} \& \mathrm{C}$ claim that after a boy has been circumcised the "raw" newly exposed glans "is continually abraded by clothing for many years." If that were true one should expect it to appear quite eroded over time. But there are no reports in the 
scientific literature of this being the case in older boys and men. H\&C follow this by stating "circumcision renders impossible any sexual stimulation involving prepuce manipulation, such as alternating eversion/gliding over the penile head." But many men have short foreskins that retract upon erection and end up as a wrinkle of skin behind the glans. Such uncircumcised men would not experience gliding. Yet there is no evidence of this being a problem for them. Would the greater stimulation a bare glans receives (in uncircumcised men with short foreskins, or circumcised men) compensate for the loss of this supposed gliding? Note that speculation about a supposed "gliding" function is at odds with findings above from large studies, RCTs, systematic reviews, and meta-analyses that have found MC is associated with either no difference or greater sexual function and pleasure.

$\mathrm{H} \& \mathrm{C}$ go on to claim that "By adulthood, the inner and outer preputial surface area varies widely, constituting $26-99 \mathrm{~cm}^{2}$ of tissue." The range reported by Kigozi et al. in the reference they cite is 7 to 100 square centimetres [83]. The average in that study was 38 square centimeters, these figures being the total for both inner and outer surfaces combined (Godfrey Kigozi, personal communication to author Stephen Moreton). The variability of the foreskin is indeed substantial. As Darwin remarked, "An organ, when rendered useless, may well be variable, for its variations cannot be checked by Natural Selection" (Origin of Species, chapter 13) [84]. H\&C go on to state that "Typical North American neonatal circumcisions remove what would constitute approximately $50 \%$ of the mean penile shaft skin length by adulthood." Given the great variability of foreskin size that is acknowledged, and the lesser variability of penis size and proportions, it is hard to fathom how a figure of $50 \%$ can be arrived at [85]. The $50 \%$ claim has been investigated in detail [86]. The evaluation showed that the statement stemmed from a study based on a small sample size, of the flaccid (non-erect) penis, and contained "loaded" wording.

$\mathrm{H} \& \mathrm{C}$ claim the foreskin is a tissue "which possesses unique protective, sensory, immunological and other important functions." Instead of scientific studies, the references they cite are virtually all articles and websites authored by MC opponents merely speculating about function. While Langerhans cells have an immunological function, they are overwhelmed when exposed to high loads of HIV, such as are encountered during coitus with an infected woman. This has been pointed out previously [87] [88] [89] [90], but was ignored by H\&C. An evaluation of the claim of immunological function concluded that:

"there are immune system-related cells and their associated biochemicals in the foreskin, just as there are in all human skin. But it no more follows from this observation that the foreskin has immune functions beyond those of any other piece of skin, or that we will suffer without them. One might as well argue that the presence of blood vessels in the foreskin means it has circulatory functions. One might also ask: if the foreskin is so immunologically important then why are males lacking one less prone to so many infections? The entire argument is a red herring" [91]. 
Next, H\&C claim that "Even if proof existed that circumcision offered significant protection against AIDS, only $0.7 \%$ of intact men studied would agree to be circumcised." But the reference they cite is to a survey of gay men in San Francisco [92]. This outlier study contradicts the vast bulk of survey data from multiple studies worldwide showing that, especially when educated about the benefits, a large proportion of men in normally non-circumcising cultures express a willingness to become circumcised. In sub-Saharan Africa, for example, a review in 2007 of 13 studies found willingness expressed by uncircumcised men to get circumcised averaged 65\% [93]. There have been many studies since then, all finding high acceptability (see [94] [95] and a list of 45 such studies [96]) To date 18.9 million men have availed themselves of VMMC in the 14 priority countries of sub-Saharan Africa [40]. In Papua New Guinea, $71 \%$ of men said they would get circumcised if it protected them from HIV [97]. MC acceptability is also high in non-circumcising China [98] [99] [100], particularly amongst medical students [101].

Willingness by men was particularly high for getting their sons circumcised (e.g., see [94] [102] [103]). Most women in different countries would encourage an uncircumcised partner to get circumcised, and most preferred circumcision for sons (see systematic reviews [104] [105]).

While serious adverse events can occur, these are uncommon, especially in early infancy [10] [106] [107]. To support their argument that "scars can be erogenous, painful or numb", H\&C cite a reference to FGM. They claim that "Circumcision per se diminishes or eliminates numerous previously referenced foreskin functions," but instead of providing evidence in support, all they do is repeat an unsubstantiated claim that the uncircumcised penis is "a dynamic self-stimulating organ with refined sensory and linear bearing/gliding capabilities." Even men with foreskins need stimulation, since the penis does not stimulate itself. What H\&C mean by "linear bearing" is unclear. And, as for "gliding," this speculative function has been evaluated in detail and dismissed [108]. We are aware, however, of a meme popular amongst MC opponents claiming "16 functions of the foreskin". These have been evaluated and shown to be based on speculation, not evidence [109].

$\mathrm{H} \& \mathrm{C}$ then suggest that men circumcised as infants somehow undergo " $p s y$ chological adaption to functional losses." But, as discussed above in relation to sexual function and pleasure, all RCT data show that almost all men circumcised as adults find no adverse effect, even an improvement, and all systematic reviews, a large British study, and meta-analyses of sexual functions find no diminution in these functions, if anything an improvement. If there is no loss of function, then there is no need to adapt to a loss, other than no longer having an apparently unimportant potentially disease-causing piece of skin. An objection raised by MC opponents is that the RCTs were of men who volunteered to be circumcised, so therefore did not value their foreskins, whereas any that did value their foreskin would not have volunteered. This has now been addressed by a large case-controlled study in Kenya in which men who volunteered to be cir- 
cumcised were compared with those who declined [110]. Changes over a period of 24 months were monitored, showing that "VMMC has no detrimental effect or may have beneficial effects on male sexual function and satisfaction for the great majority of men." Dyspareunia decreased only in circumcised men $(P<$ $0.001)$.

H\&C claim "impediments to reporting" among circumcised males because of "insufficient awareness of beneficial preputial functions (protection, sexual pleasure, immunological defense, etc)." As discussed above, there is no loss of sexual pleasure and immunological defence after MC. And as for "protection," this is irrelevant, except, perhaps, for tribesmen who normally go naked. Even though the indigenous people of Australia were found to go naked by early British settlers, the indigenous men were circumcised, because MC is part of coming of age rituals in the Koori culture. $\mathrm{H} \& \mathrm{C}$ then refer to women who have undergone FGM as not considering themselves harmed. But FGM is highly variable, and it is likely that the milder forms, such as removal of just the clitoral hood (preputioplasty) or nicking of the clitoral hood to induce a small flow of blood, have no adverse effect on sexual function or pleasure. Surgical treatment for clitoral phimosis improves sexual function in affected women [111], just as does MC for phimosis in uncircumcised men. True female "circumcision" (removal of just the clitoral hood, the latter being the female equivalent of the foreskin in males) has been recommended for improvement in sexual pleasure in women with orgasm difficulties [112] [113]. A form of female genital cutting known as labioplasty is a cosmetic procedure available in developed countries such as the USA, UK and Australia [114] [115].

Lastly in their Background, $\mathrm{H} \& \mathrm{C}$ engage in a long-winded discussion about why most circumcised men do not consider themselves harmed, or do not speak out. But $\mathrm{H} \& \mathrm{C}$ ignore the simplest explanation-they are not harmed!

\section{Methodology: Was It Appropriate?}

$\mathrm{H} \& \mathrm{C}$ admit the sample used for their online survey was not representative of all circumcised men, but rather "only of men who already consider themselves harmed by involuntary non-therapeutic circumcision." Accordingly, their self-selected sample was recruited from "foreskin restoration websites, blogs devoted to men's issues, and through genital autonomy-related social media," thus generating a biased sample of men likely to have been duped by anti-MC propaganda. Of the respondents, $17 \%$ were recruited via friends or family members, so were likely to have been influenced by the views of the person who recommended they participate. Another 28\% stumbled across it while searching the Internet, an approach that has been shown to generate anti-MC sites [54]. To add to the study's overt bias, H\&C excluded "seven submissions claiming no harm." The unrepresentative nature of the sample was further evident from the fact that "Self-reported sexual orientation found 58\% to be heterosexual, $24 \%$ homosexual, and $12 \%$ bisexual, with the remainder as either not stated, fluid, or questioning." 


\section{Results: Strength and Validity?}

\subsection{Supposed Sexual and Physical Harms}

The inherent selection bias of H\&C's study is especially evident in the sections on sexual effects and psychological/emotional effects, as we will show. Men in the survey claimed a variety of harms, which they attribute to their circumcision. However, attribution is not synonymous with confirmed cause. In their Table 2 concerning "Reports of physical harms from neonatal circumcision," the Table included "partial or total loss of the foreskin 100\%" and of "the frenulum 72\%," which is hardly surprising as the men had all been circumcised! The only problem in H\&C's Table 2 that can likely be attributed to circumcision is "little/no shaft mobility when erect; tight cut." Since the scientific evidence finds no adverse effect of $\mathrm{MC}$ on sexual function and satisfaction one might suspect that the views expressed had arisen from the "information" provided by the online groups the participants were affiliated with. "Prominent circumcision scar $(s)$ 63\%" and "Drastic skin tone variance on either side of the scar 46\%" might apply to some adult MCs, but contradicts the favourable cosmetic result and appearance consistently reported for the circumcised versus uncircumcised penis by women [105]. Moreover, skin tone variance applies to the uncircumcised penis when erect if the foreskin retracts. "Twist/bend in penis when flaccid or erect $25 \%$ " is an indication of possible Peyronie's disease rather than a consequence of MC. "Partial/total loss of penile body/shaft 10\%" is implausible as it would represent a major complication requiring further surgery, something that was rare in recent large US studies documenting all adverse events from MC [10]. The high proportion (45\%) of men reporting "Distal shaft hair (causing friction during sex)" is also implausible. Since the foreskin and glans do not have shaft hair, any hair present would be on the shaft and thus present in both circumcised and uncircumcised men. The reports of "Meatal stenosis 24\%" contradict the $0.656 \%$ prevalence of this condition in a recent meta-analysis of all studies [116]. Meatal stenosis may be as prevalent in young uncircumcised as circumcised males [117], and more common in older uncircumcised men, contributed by conditions such as balanitis and lichen sclerosis that increase with age in men with a foreskin [116] [117]. Other so-called physical harms listed seem exaggerated. One wonders whether men with an agenda might dishonestly tick more items than actually apply as part of an attempt to fuel the anti-MC message of their group. If true, this would further bias the survey. The veracity of the "physical harms" would require confirmation by a medical practitioner. Some claims of MC harm are known to be fabrications: see the "David J Bernstein" story [118] and responses by MC opponents admitting they also fabricate these kinds of stories [118].

The statement "the male prepuce is composed of highly specialised cells" is irrelevant because most cells in the body are highly specialized. H\&C then state that "circumcision removes the penile structures most sensitive to fine touch," citing a San Francisco study funded by NOCIRC [119]. Although a $P$ value of 
Table 2. Summary of publications cited that contradict claims made by H\&C.

Evidence-based policies, risks and benefits

AAP and CDC policy statements concluded that benefits exceed risks. AAP and CDC supported the right of parents to have a boy circumcised

CDC researchers found adverse events from NMC were $0.4 \%$ and virtually all minor

AAP stated the serious complications were rare $(0.02 \%)$

CDC stated benefits of NMC exceed risks by over 100:1

Over their lifetime half of uncircumcised males will experience an adverse medical condition caused by their foreskin

Criticisms of the AAP policy by MC opponents were repudiated.

Criticisms of CDC draft recommendations by $\mathrm{MC}$ opponents were repudiated

Victorians espoused MC for protection against syphilis, other STIs, phimosis, paraphimosis, balanitis, preputial adhesions, and inferior hygiene

\section{Sexual function, sensitivity and pleasure}

These do not to differ by MC status:

- systematic reviews

- meta-analyses

- RCTs

- a large British survey

Neuroreceptors for sexual pleasure (genital corpuscles) are mostly in the corona and near the frenulum, not the foreskin

Fine-touch sensitivity study by MC opponents contained serious flaws

Foreskin sensitivity does not differ from other sites

Fine touch is not relevant to erogenous sensation

Sensitivity of the glans to touch decreases with sexual arousal, thus further ruling out touch receptors in sexual sensation

Sensitivity of the penis to vibration to cause orgasm is not related to MC status

Circumcised men were non-significantly more sexually sensitive than uncircumcised men

The foreskin is not the most sensitive part of the penis to other types of sensation

Claim of sexual problems and orgasm difficulties by circumcised men contained substantial Morris et al. [138], Morris \& Krieger [61], flaws

Women prefer circumcised male partners and MC for sons (recent systematic reviews)

No difference in perception of sexual sensation between circumcised and uncircumcised men

No difference in condom use or number of partners between circumcised and uncircumcised men (review)

\section{Controversies over medical consequences of $\mathrm{MC}$}

Meatal stenosis meta-analysis found prevalence in circumcised males is actually quite low $(0.656 \%)$

Meatal stenosis occurs in both circumcised and uncircumcised males, increasing in the latter with age

Urethral strictures do not differ in prevalence between circumcised and uncircumcised infants

An anti-MC claim of 117 deaths annually from NMC in US was shown to be false

Some claims by MC opponents are fabrications

\section{References}

CDC [9], AAP [7] [8]

El Bcheraoui et al. [10]

AAP [8]

CDC [9]

Morris et al. [32] [33]

By the AAP [55]

By academics [24] [56] [57] [58]

By the CDC [62]. By academics [23] [63] [64]

Hutchinson [16] [19], Anonymous [17], Sayre [18]

\section{References}

Morris \& Krieger [61], Tian et al. [72],

Yang et al. [73],

Shabanzadeh et al. [74]

Kigozi et al. [70], Krieger et al. [71]

Homfray et al. [75]

Halata \& Munger [80], Cox et al. [76]

Waskett \& Morris [120], Bossio et al. [53]

Bossio et al. [53]

Cox et al. [76]

Payne et al. [125]

Cox et al. [76]

Bleustein et al. [126]

Bleustein et al. [126]

Meyrowitsch [139]

Grund et al. [104], Morris et al. [105]

Crosby \& Charnigo [155], Crosby et al. [156]

Moreton [157], Kabwama et al. [199]

\section{References}

Morris \& Krieger [116]

Morris \& Krieger [117]

El Bcheraoui et al. [10]

Morris et al. [67]

Moreton [118], Schaab [176] 


\section{Continued}

\section{Pain and brain}

Infants remember NMC pain only when no anesthesia is used, leading to anesthesia being recommended

No evidence of lasting brain changes, nor psychological trauma in neonatally circumcised men

No psychological problems among Swedish schoolboys circumcised for phimosis, apart from "shyness and unwillingness to undress in school gym"

A report of an "after-hours" MRI claiming brain changes from NMC was likely a fabrication

UK longitudinal study of $>5000$ males followed from birth to age 27 found no difference in developmental and behavioural indices between the circumcised and uncircumcised

New Zealand longitudinal studies found no difference in psychological outcomes between neonatally circumcised and uncircumcised males

A study claiming MC causes alexithymia was fundamentally flawed

Body dysmorphic disorder has been linked to alexithymia

Alexithymia is likely a stable personality trait not simply a consequence of psychological distress

Psychological harm may stem from anti-MC (intactivist) influence not NMC

"Foreskin restoration"

Various psychological disorders [158] [159] are more common in those circumcised men who are preoccupied by their absent foreskin

One of these may be partialism, which is an "exclusive focus on a part of the body"

Partialism is linked to alexithymia

Men preoccupied with their absent foreskin represent a subgroup within the MSM community

Legal, ethical \& human rights arguments opposing MC

These arguments are contradicted by expert evaluations

The UN Convention on the Rights of the Child supports the rights of the child to the enjoyment of the highest attainable standard of health

Since benefits greatly exceed risks, it would be unethical to leave boys uncircumcised Children have the right to preventive health care

Arguments opposing MC on the basis of "autonomy" have been refuted by ethicists

Being circumcised boosts autonomy more than constraining it

The Hippocratic Oath contains the statement, "I will prevent disease whenever I can, for prevention is preferable to cure"

\section{The nature and consequences of "intactivism"}

Suicides have been reported for circumcised men who developed psychological problems after succumbing to anti-MC rhetoric that their NMC had deprived them of a fulfilling sex life

Anti-vaccination proponents are more likely to be anti-MC and anti-water fluoridation

\section{References}

Taddio et al. [133]

Ullmann et al. [171]

Stenram et al. [173] [174]

Schaab [176]

Calnan et al. [172]

Fergusson et al. [142] [143], Moreton [144]

Morris \& Waskett [145]

Fenwick \& Sullivan [147]

Taylor et al. [148]

Circumcision Choice [153]

\section{References}

Mohl et al. [146]

Kafka [159], American Psychiatric Association DSM-5 [158]

Fenwick \& Sullivan [147]

Mohl et al. [146]

\section{References}

Rivin et al. [23], Morris et al. [24], Benatar \& Benatar [44] [45], Bates et al. [46], Benatar [47], Jacobs [48], Jacobs \& Arora [49], Bester [50]

United Nations Human Rights Office [178]

Bates et al. [46], Jacobs [48]

Rivin et al. [23]

Benatar [47], Jacobs [48], Jacobs \& Arora [49], Bester [50], Clark et al. [179], Mazor [180]

Brusa \& Barilan [181]

Johns Hopkins University [187]

\section{References}

Bay Area Intactivists [194], Intaction [195]

Hoffman et al. [163] 
0.014 was obtained in that study, after correction for multiple testing the $P$ value became non-significant [120]. The critics used the study data to compare 9 locations common to the circumcised and uncircumcised penis, and found no significant difference, even without correction for multiple testing [120]. Aspects of study design, including modes of subject recruitment, were also criticized. All skin has touch receptors. The fine-touch of the foreskin does not differ from that in the forearm and other sites tested [53]. The foreskin, just as other skin on the body, contains sensory receptors that respond to touch, temperature and pain, but none of these other types of sensation were studied by Sorrells et al. [119].

We take issue with H\&C's speculative statement that "the relatively larger, densely innervated and more functionally dynamic male prepuce-while anatomically equivalent to the female prepuce-may be more analogous to the clitoris as a source of pleasure." In the absence of scientific evidence, their reference 96, used as support, is to a YouTube video by MC opponent James Loewen featuring retired pathologist Ken McGrath. McGrath engages in rampant speculation, unfounded assertions, and makes comparisons between fingertips and foreskins. The lack of scientific references to his assertions is striking. It should be noted that McGrath has a history of making questionable claims. He was the source of the myth that the foreskin contains 10,000 nerve endings, and the likely source of the myth that it contains 70,000 . He has since conceded that his value of 10,000 was an order of magnitude too high [121].

H\&C's claim that MC in infancy reduces penis size was based on a small 1995 study that found a $5 \%$ difference in erect penile length between circumcised and uncircumcised Australian men aged 18 - 55 years [122]. But, the sharp decline in MC from the mid-1970s in Australia meant the circumcised men were older on average, therefore introducing the possibility of confounding. A decline in testosterone with age may contribute to a slight reduction in penile size. Erectile dysfunction increases with age and is associated with penile shrinkage. A portion of older circumcised men might not have been able to maintain as firm erections as younger men. Since the study relied on self-measurement, the presence in a portion of uncircumcised men of a foreskin that overhangs the glans during erection may have led to higher estimation of penile length for uncircumcised males overall. Another study noted a 5.7\% lower erect penile length of men (mean age 22 years) circumcised neonatally compared to non-neonatally [123]. In the absence of a mechanism to explain such an effect this unreplicated result should be treated with caution.

H\&C again "cherry-pick" a figure of " $5 \%$ - 20\%" for meatal stenosis in circumcised males. They took this frequency range from the Introduction of an article by MC opponent, Morten Frisch [124], and embellish it with the false claim that meatal stenosis is found "almost exclusively" in circumcised males. In fact, in Frisch's study there was no difference in meatal stenosis frequency between circumcised and uncircumcised males, and in older uncircumcised males meatal stenosis was more prevalent, most likely as a result of inflammatory skin conditions that are much more common in uncircumcised males (see critique of the 
Frisch study [117]). As noted earlier, a meta-analysis of all studies found overall prevalence of meatal stenosis to be $0.656 \%$ in circumcised males, this being non-significantly higher than in uncircumcised males, perhaps because of underestimation in the uncircumcised males [116]. Although the meta-analysis was published after H\&C's study, the articles used for the meta-analysis were already available. Also available to $\mathrm{H} \& \mathrm{C}$ were studies showing meatal stenosis is a common complication of lichen sclerosis, which in turn is a common reason for medical MC. Males circumcised for lichen sclerosis would switch groups, therefore unduly raising meatal stenosis prevalence figures for circumcised males. This source of confounding likely explains some of the apparent association. Diagnostic bias has been suggested, in that it is easier to see whether the urethral opening is narrow if there is no foreskin to obscure the view [116] [124].

\subsection{Histological Correlates of Sexual Pleasure}

$\mathrm{H} \& \mathrm{C}$ then return to the study by Sorrells et al., and refer to a $2015 \mathrm{PhD}$ thesis by Jennifer Bossio, but not her research in Journal of Urology measuring "penile sensitivity in neonatally circumcised and intact men using quantitative sensory testing" that led her and her co-authors to conclude that "this study indicates neonatal circumcision is not associated with changes in penile sensitivity" and "challenges past research [by Sorrells et al.] suggesting that the foreskin is the most sensitive part of the adult penis" [53]. $\mathrm{H} \& \mathrm{C}$ go on to state "The impact of circumcision on a man's ejaculation latency time, i.e. whether he experiences premature or delayed ejaculation, may be attributable to altered sensation in the surgical scar," citing Sorrells et al. who did not in fact study this. In contrast, as referred to earlier, high quality evidence that includes RCTs [70] [71], systematic reviews [61] [72] [73] [74], and a meta-analysis of sexual dysfunctions in men [72] [73] found no difference between men of each circumcision status, the more recent of these finding 58\% lower erectile dysfunction in circumcised men [73]. All but the most recent of these articles were available to $\mathrm{H} \& \mathrm{C}$ but were ignored in favour of one weak study.

The density of "fine-touch" receptors (Meissner's corpuscles) in the foreskin diminishes at puberty when male sexual activity is increasing, so these receptors are unlikely to be involved in sexual sensation [76]. Moreover, free nerve endings (that also respond to touch) show no correlation with sexual response. Sensitivity of the glans to touch decreases with sexual arousal, thus further ruling out touch receptors in sexual sensation [125]. Sensitivity of the penis to vibration, which is able to elicit arousal and ejaculation, is not related to MC status [76]. Fine touch is not relevant to erogenous sensation [76]. Circumcised men were non-significantly more sexually sensitive than uncircumcised men [126]. The foreskin was not the most sensitive part of the penis with respect to other types of sensation [126].

In contrast to the foreskin, the glans and underside of the proximal shaft are the sites of neuroreceptors responsible for sexual sensation. The glans has a unique corpuscular receptor, consisting of axon terminals that resemble the tan- 
gled skein of free nerve endings, and that are probably derived from Krause's end bulbs [127]. Genital corpuscles of the glans are most abundant in the corona and near the frenulum [80]. Confusion has been pointed out between the genital corpuscle and Meissner's corpuscle [128]. The genital corpuscles are the mediators of sexual response. They are connected to a unique innervation system, which is quite separate from that of the prepuce, but does involve the meatus [129]. By exposing the glans, MC should increase sexual pleasure [76].

In claiming "changes in penile reflexes" caused by $\mathrm{MC}, \mathrm{H} \& \mathrm{C}$ cite a study on the penilo-cavernosus reflex being more difficult to elicit in middle-aged circumcised Slovenian men [130]. The study assessed the sacral (i.e., bulbocavernosus) reflex in men with suspected neurogenic causes of bladder, bowel or sexual dysfunction by, "brisk compression of the glans penis between the first three fingers." But neurophysiological testing did not find a difference. The article noted, moreover, that the finding was not consistent with data from the US, where most men are circumcised and the penilo-cavernosus reflex can be elicited by clinical testing in $98 \%$ of men [131]. Although the author described how the 30 circumcised and 15 uncircumcised men with retracted foreskins were identified, he did not comment on why data for only 29 of the 202 uncircumcised men with their foreskin in place were presented, and no demographic information was provided [130]. A systematic review of MC and sexual function [61] rated this study as low quality.

\subsection{Are There Psychosexual Harms?}

In support of H\&C's assertion about "the impact of pain from the procedure on response to subsequent painful stimuli" they cite a monograph by an MC opponent and a small study by Taddio and co-workers that found neonatally circumcised infants exhibited greater pain scores to routine vaccination at age $4-6$ months [132]. But H\&C fail to cite a larger study by the same authors that found "Among the circumcised group, preoperative treatment with Emla attenuated the pain response to vaccination," leading them to state: "We recommend treatment to prevent neonatal circumcision pain" [133]. As a result, the AAP recommended the use of local anesthesia for infant $\mathrm{MC}$ in its subsequent guidelines. $\mathrm{H} \& \mathrm{C}$ then refer to “Bossio's findings regarding the man's feelings about what was done to his penis." But the reference cited is a $\mathrm{PhD}$ thesis (referred to above), not a peer-reviewed journal publication, and, as mentioned earlier, had design flaws relating to recruitment via social media, known to attract, and be flagged by, anti-MC lobby groups to skew the results.

\subsection{Lubricants May Enhance Sexual Pleasure}

In their Table 3, $\mathrm{H} \& \mathrm{C}$ provide results they obtained for "Reports of sexual harms from neonatal circumcision." The first survey item was "Dry/keratinized glans requiring lubricants 75\%," but "dry" and "keratinized" are not the same thing. A person's body is dry, until they step into a shower. Thus, use of the word " $d r y$ " seems irrelevant. No difference in keratin staining was found in a histological 
study published in the $B M J$ [134]. For more on this topic see reference: [135]. As for needing lubricants, this is an under-researched area, although an Internet survey of 603 males aged $\leq 21$ years found $34.9 \%$ of circumcised males and $19.7 \%$ of uncircumcised males used lubricant [136]. The survey speculated that in uncircumcised males the foreskin slides over the glans during masturbation, but in circumcised males sliding a dry hand over the penile skin may cause friction that is reduced with lubrication. The fact that a slightly lower proportion of uncircumcised males use lubricant begs the question, do some males use lubricant because they need to, or because it enhances pleasure? Its use would likely be helpful for those with a tight circumcision, but one might suspect that for many men it is simply an enjoyable, optional extra, made easier when there is no foreskin in the way. More studies are needed. Most of the other "sexual harms" $\mathrm{H} \& \mathrm{C}$ list in their Table 3 are contradicted by the best available evidence (see the reviews cited above). No one denies surgical complications from MC occasionally happen. Given the biased nature of the sampling, it is inevitable that it will draw in the small proportion of men who have suffered a complication, as well as those suffering problems they erroneously attribute to MC. But many of the problems listed by $\mathrm{H} \& \mathrm{C}$ occur at similar frequency in uncircumcised males, showing that $\mathrm{MC}$ is not to blame.

\subsection{Psychological Aspects}

The survey by Frisch et al. that $\mathrm{H} \& \mathrm{C}$ cite reporting that "circumcised men experience more frequent orgasm difficulties" and that their female sexual partners more often report "orgasm difficulties, dyspareunia, and a sense of incomplete sexual needs fulfilment" [137] has been the subject of substantial criticism published in the same journal [138]. It was also criticized by a Danish epidemiologist because the men affected were circumcised for medical problems which had likely impaired their sexual function already [139]. Professor Michael King of University College London, described the effect as "tiny" and the results "over-analysed," to which Frisch conceded that "most circumcised males and their female partners were fine" [140]. A one-sided presentation by Morten Frisch on his study is available in a YouTube video in which he states that "most circumcised men, and most women with circumcised spouses, do not encounter a whole lot of sexual trouble. That I want to stress to avoid stigmatisation" [141]. Weak, "cherry-picked" studies are cited by H\&C, but not critiques that have undermined these, as can be found in the Discussion of a systematic review in the world's highest quality sexual medicine journal [61], and the findings of RCTs and other high quality studies cited above.

In their Table 4, H\&C report data supposedly finding evidence of "psychological/emotional harms from neonatal circumcision." But this reads like a page from an anti-MC manifesto that tells vulnerable men the "harms" caused to them by their neonatal MC. Those men who naïvely believe such a narrative may become upset and respond in the way many have to the questions in H\&C's Table 4, even though proper well-designed studies have found no evidence for ad- 
verse psychological effects of neonatal MC [142] [143]. As mentioned earlier, individuals having a strong opinion about $\mathrm{MC}$ would be more likely to participate in the H\&C survey, thus introducing a risk of bias. "Victimism" may be a result for individuals who are caught up in the anti-MC movement. Encounters with anti-MC literature can result in some men becoming convinced of being victimized. H\&C's Table 4 fuels a speculative belief that the circumcised man has been betrayed by his father, mother, doctor, clergy or others. Some men may have deeper psychological issues and may project their problem on to various targets.

The items in H\&C's Table 4 and the results thus lead us to question the validity of the findings. Claims of adverse psychological effects are supported only by weak studies, opinion pieces and anecdotes. Well-designed longitudinal studies of a New Zealand cohort examined annually from age 1 to 16 years and at ages 18, 21 and 25 years found no difference in psychological outcomes and other adverse effects between uncircumcised and neonatally circumcised males [14] [144]. The alexithymia claim H\&C cite involved an advertisement on anti-MC websites asking for volunteers for a study on "Male circumcision trauma," therefore biasing the study cohort. Critics exposed numerous other fundamental flaws in that study [145].

A major factor that can explain many of the participant's views in H\&C's Tables 3 and 4 is suggestibility. Suggestibility is a person's tendency to assume and espouse the views of another person. Hearing the same anti-MC mantras repeatedly will likely increase belief in the mantras by vulnerable men.

Psychiatric problems appear to be more common in men unhappy at having been circumcised [146]. Body dysmorphic disorder has been linked to alexithymia [147]. Consistent with bias in the small self-selected sample, the overall rate of alexithymia was over 3-times higher than seen in the general population [145]. There was, moreover, no association between age of MC and alexithymia. There is strong empirical support for alexithymia being a stable personality trait rather than simply a consequence of psychological distress [148]. A large survey evaluating a comprehensive array of emotional problems in pre-school [149], and in 6 - 16 year-old [150] children from 24 different societies found differences in severity of these between countries, irrespective of MC prevalence in each. While some, but not all [151], studies have shown that men exhibit higher alexithymia scores than women, the difference is seen in countries with divergent MC rates [145]. In response, the study authors concede "the potential for selection bias" was a primary weakness of their study [152]. Such a weakness applies to H\&C's survey.

$\mathrm{H} \& \mathrm{C}$ again refer to Bossio's $\mathrm{PhD}$ thesis in claiming "circumcised men are less likely to be happy with their circumcision status than intact men." Since subjects were recruited, in part, via social media, Bossio's study risked recruitment bias as discussed above. As mentioned earlier, a survey by YouGov involving already-registered participants, therefore avoiding bias, found the reverse, with $86 \%$ of men happy at having been circumcised and $29 \%$ of uncircumcised men 
wishing they were circumcised [77]. H\&C note their own findings and those of Bossio in respect of psychological genital image and self-esteem of neonatally circumcised homosexual men.

The assertion by H\&C that "Insensitive parental attitudes appear to be changing, however, as social media sites expressing parents' circumcision regret are proliferating" can be taken as meaning that MC opponents have become increasingly successful at convincing gullible parents into thinking that they have harmed their sons by having had them circumcised. Can we now expect "studies" by $\mathrm{H} \& \mathrm{C}$ and other MC opponents on the psychological harm suffered by parents regretting their decisions to have their sons circumcised, but without any acknowledgement that such "harm" may actually be due to false beliefs promoted by MC opponents? Cassie Waldeck, press secretary of the anti-MC group "Bloodstained Men and their Friends" stated in a Facebook post on July, 26 2016 that she has known many "regret mums" who have considered suicide over what they think they did to their sons by having them circumcised. An appraisal of psychological harm stemming from anti-MC influence is available [153].

\subsection{Greater Sexual Activity of Circumcised Men}

The representative National Health and Social Life Survey of 1410 US men aged 18 - 59 years found that sexual dysfunctions were more common among uncircumcised men [154]. This was slight at younger ages but became more frequent later in life. It found that circumcised men engaged in a more elaborate set of sexual practices, suggesting they enjoyed a more varied sexual lifestyle, and that their female partners were more pleased with the esthetics of a circumcised penis [154]. H\&C are particularly drawn to a finding that circumcised men masturbate $40 \%$ more often than uncircumcised men and have more oral and anal sex. Aside from laying to rest the Victorian myth that circumcision helps prevent masturbation, the finding by Laumann et al. [154] suggested that, if anything, $\mathrm{MC}$ enhances the sexual experience. But $\mathrm{H} \& \mathrm{C}$ speculate that the findings indicate that "Some circumcised men resort to oral/anal sex to compensate for penile desensitisation when vaginal intercourse is insufficiently stimulating." A reason for more frequent fellatio may be because of the strong preference by women for a circumcised penis for such activity, as found in a recent systematic review of all studies [105], and by Bossio et al. in her study [52]. Better health and hygiene (no smegma) appear to be major reasons. There is in fact no good evidence for penile desensitization after MC. In fact, as discussed above, high quality evidence indicates no change or an improvement. Laumann et al. state in their paper that whilst circumcised men engaged in more varied sexual practices, "This pattern differs across ethnic groups, suggesting the influence of social factors." Therefore, the causes may not necessarily be directly related to MC status.

$\mathrm{H} \& \mathrm{C}$ go on to cite a study by MC opponent, Frisch, that found "circumcised men were more likely than uncircumcised men to report a lifetime history of 10 or more partners." But rather than interpreting this as women's preference for circumcised men for sexual activity, $\mathrm{H} \& \mathrm{C}$ make the astonishing convoluted 
suggestion that "circumcised men are compensating for decreased quality of sexual experiences with increased variety and quantity." It is unlikely that circumcised men would complain that they get more sex!

\subsection{Condom Use}

$\mathrm{H} \& \mathrm{C}$ 's study found that "condoms were not an option for [neonatally circumcised men] due to exacerbated loss of sensation." They cite as support "two recent studies [in which] Crosby confirmed that circumcised men were significantly less likely than intact men to wear a condom when engaged in penetrative intercourse." But Crosby \& Charnigo expressly ruled out differences in perception of sensation between circumcised and uncircumcised men [155]. Instead they linked lower condom use by circumcised men to confidence, lower condom use being seen only in men aged less than 25 years, and that this disappeared as the men matured.

In their Discussion, Crosby \& Charnigo state:

"Although the scale measure of sensation perceptions did not vary significantly by circumcision status, intact men were more likely to have complete confidence in their ability to use condoms than circumcised men. This observation suggests that intact men may, for some reason, have gained information or skills associated with condom use that their circumcised counterparts lacked."

And in their Conclusion, Crosby \& Charnigo state:

"However, even after controlling for circumcision status and age, confidence predicted condom use, suggesting that intervention programmes should focus on building men's confidence in their ability to use condoms. On the other hand, differences in condom use frequency between intact and circumcised men may dissipate after age 25, and sensation-related aspects of condom use may not differ between intact and circumcised men attending STI clinics."

Crosby \& Charnigo specifically provided data relevant to sensation (see their Table 1), and although scores for adverse perceptions were actually higher for uncircumcised men, there was no statistical difference. A subsequent study, of Afro-American MSM, found no difference between men of either MC status in problems with condom use or perception that condoms detracted from sexual pleasure [156]. We therefore strongly dispute the use by H\&C of the findings by Crosby and Charnigo as support for their contention that circumcised men avoid condoms because of sensation issues. The suggestion by H\&C of "diminished likelihood of condom use among circumcised men" as "cast [ing] doubt on the efficacy of circumcision as a means of STI/HIV controP" is contradicted by the fact that most studies have found no difference in condom use between circumcised and uncircumcised men [157]. The claim by H\&C of "increased sexual compulsivity" is also contradicted by data showing no difference in number of partners in the studies of VMMC for HIV control [157].

\subsection{Partialism and "Foreskin Restoration"}

$\mathrm{H} \& \mathrm{C}$ found $76 \%$ of their respondents "reported talking to other men [suppo- 
sedly] harmed by circumcision, while 64\% of respondents sought no help or treatment from professionals." Of the latter, only $29 \%$ of professionals were sympathetic or helpful, while $25 \%$ were dismissive. There is evidence that various psychological disorders [158] [159] are more common in those circumcised men who are preoccupied by their absent foreskin [146]. A psychopathology term that fits with having a sexual obsession with the (missing) foreskin is termed "partialism," which is an "exclusive focus on a part of the body" [159] (see the American Psychiatric Association's Diagnostic \& Statistical Manual 5th Revision (DSM-5) [158] under "Paraphilia not Otherwise Specified" (ICD-10 code CM F65.9) in the sexual and gender Identity Disorders Section.) A diagnosis of paraphilia is made if "the behavior, sexual urges, or fantasies cause clinically significant distress or impairment in social, occupational, or other important areas of functioning." These included narcissistic and exhibitionistic body image, depression, major defects in early mothering and ego pathology. H\&C mention that men unhappy with being circumcised were likely to undertake "foreskin restoration," an undertaking that involves stretching the skin on the shaft of the circumcised penis using weights. A study of men having a preoccupation with their absent foreskin represented a subgroup within the MSM community [146]. Mohl's detailed analysis of psychiatric aspects of men seeking foreskin restoration indeed noted the above symptoms of narcissistic and exhibitionist body image, depressions, major deficits in early mothering, and ego pathology [146]. The current anti-MC mantra about loss of sexual pleasure owing to having been circumcised as a reason for "foreskin restoration" was not mentioned in Mohl's 1981 study. H\&C also refer to body dysmorphic disorder. This condition has been linked to alexithymia [147]. Of the 1200 members of an organization devoted to "foreskin restoration," $80 \%$ were homosexual, 10\% were bisexual, and $10 \%$ were heterosexual [147]. The overall membership comprised $65 \%$ who were uncircumcised, $30 \%$ who were circumcised and $5 \%$ who were partially circumcised. Although many were happy with the result, thus justifying to themselves the decision to undertake this arduous procedure, others disliked their new genital status, even choosing to undergo re-circumcision [160] [161]. Some required medical attention for resulting genital mutilation [160] [162]. Men reporting improvements following restoration may be experiencing a placebo effect.

\subsection{Threats and Retribution}

The finding in H\&C's Table 9 of "Reports of desired retribution against physicians performing non-therapeutic circumcision" is consistent with similar sentiments, and threats, expressed on social media, as revealed in a recent study of Facebook comments by anti-vaccination proponents, who were found to be more likely to be anti-MC and anti-water fluoridation [163]. The anti-MC and anti-vaccination movements share similar features: casting doubt on the validity of the scientific method, employment of anecdotes and "junk science," demonizing anyone who dares disagree with their beliefs, and resorting to specious 
arguments and twisted logic. They dogmatically adhere to the same mantras of the group while ignoring the ever-strengthening scientific evidence. Coalescence around common beliefs likely increases the group's cohesion, and the development of in-group and other-group attitudes. Philosophically, they tend to espouse the "nature is infallible" belief, otherwise known as the "appeal to nature" fallacy.

Such sentiments should be taken seriously as a real threat to medical professionals, as indicated by that other controversial medical procedure-abortion. Abortion clinics have been bombed and their staff murdered [164]. Pseudoscientific articles portraying MC in a bad light have the potential to fuel violent thoughts leading to criminal acts against MC proponents and practitioners. Alarmingly, MC opponents have openly discussed this possibility [165], and have compiled a list of medical professionals who provide MC services, with inflammatory details as well as their addresses and other contact details [166]. Many of these medical practitioners have suffered inexcusable abuse and harassment.

\section{Discussion: Validity of Implications of the Survey Findings}

\subsection{False Calculations of Complications}

$\mathrm{H} \& \mathrm{C}$ cite a 26-year-old study [167] reporting an unrealistically high " $2 \%-10 \%$ complication rate for medicalized circumcision" to calculate that "globally between 13 million and 65 million males suffer circumcision complications of the types described by [their] respondents." But that study in turn, is a secondary source, and cites 3 papers from the 1980s for its estimate of $2 \%-10 \%$. Not only are the data decades old, they are based on studies of only $100-140$ individuals, involved older boys rather than neonates, were for medical indications (mostly phimosis), used general anesthetic that increases risk, and reported that there were no serious complications. $\mathrm{H} \& \mathrm{C}$ fail to cite large detailed studies of adverse events such as by CDC researchers (mentioned above) that found a rate of $0.4 \%$ in infants (mostly neonates), virtually all being minor, easily and immediately treatable, with complete resolution [10]. In boys aged 1 - 9 years adverse event frequency was 20 -fold higher, and was 10 -fold higher for males aged $\geq 10$ years [10]. Findings were virtually identical in a recent large California study [168].

$\mathrm{H} \& \mathrm{C}$ go on to apply their misleading " $2 \%$ - $10 \%$ " figure to the USA, even though MC in the US is most commonly performed in neonates. The study by CDC researchers also documented adverse conditions experienced by uncircumcised males and found prevalence was not insignificant. Risk-benefit analyses have found benefits of early infant MC exceed the risks of an adverse medical condition over the lifetime by 100 - 200 to one [32] [33].

They refer to the high risk of complications for non-medical tribal circumcisions, but these would apply to very few, if any, of their respondents. Their statement that "There are no studies of long-term adverse physical, sexual, psychological or self-esteem effects on boys and men from foreskin excision" is un- 
true. There are in fact numerous high-quality studies showing no long-term adverse physical, sexual, psychological or self-esteem effects of neonatal or later-age MC, as we have cited above, but which $\mathrm{H} \& \mathrm{C}$ have ignored. $\mathrm{H} \& \mathrm{C}$ seem to be begging the question by assuming there are adverse effects. As cited repeatedly above, all high-quality studies of sexual function and satisfaction have found no difference between circumcised men, most of whom were circumcised neonatally, and men who were uncircumcised. RCT data and findings from longitudinal studies of men circumcised as adults have found a large majority of men reported no difference or an improvement after circumcision. H\&C cite claims by the late Robert Darby, in an article in which he criticizes the AAP's 2012 infant MC policy, of "inherent harms associated with the loss of the prepuce itself or later recognised adverse outcomes to sexual/emotional health or self-esteem" [169]. They fail to cite an extensive critique of Darby's article which accused him of "speculative claims about the foreskin and obfuscation of the strong scientific evidence supporting pediatric policy development" [57].

\subsection{Brain Damage?}

$\mathrm{H} \& \mathrm{C}$ refer to " $A$ biocultural analysis describe[ing] childhood circumcision as 'low-grade neurological castration' resulting in traumatic neurological reorganisation andlor atrophy of brain circuitry." The study they cite is an article that provides no experimental or observational evidence, only speculation, about what the authors think MC might do [170]. That H\&C repeat unproven or discredited claims about keratinization and desensitization does nothing to bolster their credibility. A recent study found no evidence that MC causes lasting brain changes, nor that it causes psychological trauma [171]. A longitudinal study in the UK, beginning in 1946, of more than 5000 individuals followed from birth to age 27, found no difference in developmental and behavioural indices between circumcised and uncircumcised males [172]. Taken together, these consistent findings in different populations support an absence of an effect of MC on cognitive ability.

In Swedish schoolboys circumcised for phimosis, no signs of psychological problems were found apart from "shyness and unwillingness to undress in school gym" in a setting in which MC is uncommon [173] [174]. Next, H\&C mention that "one unpublished study recorded infant brain changes post circumcision," citing an account on an anti-MC website of an "after-hours" MRI brain scan of a single infant before and after NMC without anesthesia that claimed to reveal changes in parts of the brain associated with reasoning, perception and emotion [175]. Ethical approval, logistics and compliance with procedural guidelines were not stated, suggesting that there were none. The mother was strongly opposed to MC, leading critics to question her approval for this experiment and to an assertion that the on-line report by a $\mathrm{MC}$ opponent was a fabrication [176]. H\&C appear unaware of the irony of their comment about mothers "disregard[ing] their own powerful maternal instincts to protect their 
sons from a surgery shown [!?] to disrupt the maternal-infant bond." In support of the latter they cite an opinion piece in a religious magazine, and a study that "examined 43 discreet behaviours relating to feeding, gaze, facial expression, vocalizations and touch" in the first 24 hours post-circumcision comparing 27 newborn infants circumcised without anesthesia with 32 uncircumcised infants (who were circumcised subsequent to the 24 hour study period) [177]. The study "revealed no major behavioural differences between the experimental and control groups" and that "circumcision has brief and transitory effects on (2 of the 43) mother-infant interactions," these two being not statistically different between each group. H\&C should also have cited a New Zealand study of 635 neonates in which "circumcision was not significantly associated $(P>0.05)$ with breastfeeding outcomes, even after adjusting for covariates" [143].

\subsection{Consent, Rights and Ethics}

The issue of consent for childhood MC is raised by H\&C, who strive to depict the procedure as detrimental, as involving parents having to guess "about their son's future wishes" and comparing it to female genital cutting/mutilation. But their arguments ignore the scientific evidence of lifetime benefits which also apply to childhood vaccination and the rights of parents to protect the health of the child. Scholarly assessments suggest that circumcision of male minors is ethical [44]-[50]. Given the wide-ranging protection against multiple medical conditions and infections in infancy and childhood, including STIs in boys who become sexually active, some have argued that it would be unethical to leave boys uncircumcised [46] [48]. As pointed out by Jacobs [48], The UN Convention on the Rights of the Child (CRC) Article 24 (1) states:

"States Parties recognize the right of the child to the enjoyment of the highest attainable standard of health... States Parties shall strive to ensure that no child is deprived of his or her right of access to such health care services" [178].

As mentioned earlier, Article 24 (3) of the CRC might be interpreted as mandating MC, given that not circumcising boys has been deemed as prejudicial to their health. H\&C's assertion that physicians only perform circumcisions for financial benefit is offensive, as such an assertion would apply to everything a medical practitioner does as part of his or her professional duties. The procedures and practice of medical professionals are regulated to ensure ethical guidelines are followed.

Arguments made about so-called "rights" pale into insignificance when compared to the right to preventive health care [23]. And as for "autonomy," arguments opposing MC on this basis have been refuted by authorities in ethics [45] [47] [48] [49] [50] [179] [180], where it has been argued that being circumcised boosts autonomy more than constraining it [181]. Legal, ethical and human rights arguments by ARC lawyers Peter Adler [182] and Steven Svoboda [183] attempting to undermine the CDC's draft MC policy [59] [184] and the AAP's 2012 MC policy [7] [8], respectively, have been evaluated in great detail by Pro- 
fessors of Law, Bioethics, Medicine, Urology and Medical Sciences and were found to be "flawed scientifically, ethically and legally, and should be dismissed as endangering public health and individual well-being," as follows: CDC policy [23] and AAP policy [24]. Criticisms of the AAP policy as "culturally biased" by anti-MC campaigner, Frisch, with co-authors mostly in Northern Europe, were dismissed by the AAP Task Force because the evidence points to cultural bias being in Europe rather than in the USA [55]. Criticisms of the AAP policy by Svoboda and Van Howe [185] were shown to be flawed [56]. Criticism of the AAP policy by Darby [169] was also repudiated [57]. A paper by ethicist Earp [186] criticizing the CDC guidelines was similarly shown to be flawed [63].

\subsection{Hippocratic Oath}

The Hippocratic Oath contains the statement, "I will prevent disease whenever I can, for prevention is preferable to cure" [187]. Disease prevention is central to the affirmative policy recommendations of the AAP and the CDC. These policies have now raised the bar, meaning that medical organizations elsewhere can no longer rely on opinions, but must henceforth consider the extensive high-quality scientific evidence as an integral part of developing $\mathrm{MC}$ policies. The arguments made by $\mathrm{MC}$ opponents disagreeing with AAP and CDC policies have been consistently rebutted. Unless, as seems unlikely, any new opposing argument emerges, it would appear the time has now come for the infant MC critics to desist [24].

\subsection{Recruitment Bias}

In their section "Answers prompt more questions," H\&C admit that the "present survey findings are limited to a self-selected subset of men." Recruitment for the $\mathrm{H} \& \mathrm{C}$ study was via Hammond's web-based "Global survey of circumcision harm," website [188]. Despite taking place in 2011 and 2012, the results were not published until 5 years later [12]. The survey with its "loaded" title states that "The Global Survey of Circumcision Harm is open to any man age [sic!] 18 or older who was circumcised as a child and believes or knows he was harmed by circumcision" [189]. In other words, only those who were, or believe they were, harmed by MC can participate! The expected, and likely very large, majority of happy circumcised men not "harmed" were excluded. Or to put it another way, it is a poll of those who have fallen for the anti-MC narrative to see how many fallacies they believe. The bias in this convenience sample is further evident from the non-representative composition of the participants, with $43 \%$ having found out about it from anti-MC websites, $13 \%$ from a friend (likely to be an MC opponent), $28 \%$ from searching the Internet (which is highly prone to bring up anti-MC websites, as explained in the article by Stern "How circumcision broke the internet" [54]) and 8\% from "men's organization/media" (which tend to be anti-MC). It is notable that $36 \%$ of the participants were MSM, which vastly exceeds the population prevalence of MSM. The same over-representation of MSM 
was noted by critics of other such surveys, such as a statistically flawed [190] survey in Belgium in which 14.2\% of participants were MSM [191].

\section{6. "Loaded" Questions and Exaggerated Responses}

The questions in the survey were also "loaded." Many of the supposed "harms" had nothing to do with MC. For example, sexual problems also affect uncircumcised men, and do so to a similar extent as circumcised men, as shown by meta-analyses of all studies [72] [73]. Many questions were subjective, or require comparison-for example, how does a man circumcised as a baby know he has lost sensation if he has never experienced the uncircumcised state? Self-reporting is prone to bias. Some do not even know their MC status, as found in a study in Texas of males aged $15.0 \pm 1.6$ (mean \pm SD) years in which $7 \%$ thought they were uncircumcised, whereas physical examination revealed they were circumcised, and 23\% did not know their MC status [192]. At least those in the survey who provided photographs could have their MC status verified. In the absence of verification, survey answers by men with an anti-MC agenda may be exaggerated or even false. The survey asked for a response to the statement "As I first learned understood [sic!] what circumcision really was, my reaction was," with mostly negative options for the respondents to choose from. Aside from the poor grammar, one might wonder what is meant by "what circumcision really was"? Presumably whatever H\&C think it is, not what the medical definition is. Thus, to step back, one might be forgiven for drawing a comparison with surveying anti-vaccination proponents for their opinions on vaccination.

\subsection{Are There More Questions to Address?}

The first item in H\&C's “Answers prompt more questions" list of questions refers to "beneficial foreskin functions," but fails to delineate what these are. What functions? And what happens when males are misled by bogus claims by MC opponents about supposed functions as well as other foreskin fallacies? Item 2 suggests the need for research addressing, "To what extent does unwanted circumcision contribute to parental alienation?' We ask to what extent do anti-MC claims contribute to this? As an example, we refer the reader to an online Q\&A forum [193] and the abhorrent replies by MC opponents that appear on that webpage.

The question in item 4, "Are there disparities between brain functioning in genitally intact $v$. neonatally circumcised males" has already been answered in the study by Ullmann et al. that:

"found no differences in long-term limbic-hypothalamic-pituitary-adrenal axis activity, subjective stress perception, anxiety, depressiveness, physical complaints, sense of coherence and resilience. Rather, an increase in the glucocorticoid levels indicated a healthy lifestyle and appropriate functioning. Thus, our findings provide evidence that male circumcision does not promote psychological trauma" [171]. 
As to the other questions $\mathrm{H} \& \mathrm{C}$ suggest for further research, many do have merit. MRI scans might well be worthwhile (if only to show no difference), and the effects of MC on "gay men's" experience is quite under-researched. It is intriguing that so many MSM participate in surveys like the present one by $\mathrm{H} \& \mathrm{C}$. Hammond is a gay rights campaigner.

\subsection{Tragic Outcome of Belief in Anti-MC Fallacies}

H\&C's last item asks, "As a result of concerns about their unwanted circumcision, how common is suicidal ideation (or actual attempts) among adult and teenage males?' Given that two young men living in San Francisco, Jonathon Conte in 2016 [194] and Kevin Cagle in 2015 [195], have committed suicide, evidently, in the case of Conte, and possibly, in the case of Cagle, as a result of having been duped by the propaganda of MC opponents, one has to ask if those suicidal thoughts are the result of negative opinions about MC having been embedded in the psyche of impressionable males deceived by the false anti-MC ("intactivist") claims [196]. Robert Darby, an elderly historian known for his anti-MC publications that have been consistently debunked, committed suicide in 2019. We are unaware of the reason, however.

To "Potential responses to the current survey findings may include," $\mathrm{H} \& \mathrm{C}$ suggest a need to "Create support groups and outreach to men suffering from their circumcision." If such support groups merely disseminate the emotive mantra of MC opponents attempting to convince others that MC is all things bad, then such "support groups" will do more harm than good. Conte became a prominent MC opponent and his obsession eventually caused him to kill himself.

\section{Conclusions}

We find the survey by $\mathrm{H} \& \mathrm{C}$ to be substantially one-sided. It solicits answers from a "loaded" sample of individuals who are unrepresentative of the general population of circumcised males. This leads us to question whether the study and its reporting are dispassionate. Tim Hammond is a lay anti-MC activist who states that he previously published a preliminary survey in a 1999 issue of $B J U$ International [14], while not disclosing that the relevant issue of that journal was devoted to articles by individuals responding to a call for papers opposing MC. His article in BJU International states his affiliation as "National Organization to Halt the Abuse \& Routine Mutilation of Males (NOHARMM), San Francisco, California, USA" [197]. In the present article, he states that he is "an independent researcher and co-founder of the Canadian non-profit Children's Health and Human Rights Partnership" [12]. Adrienne Carmack is also a prominent anti-MC activist, and has been praised by the anti-MC movement [198].

Our critical evaluation finds substantial flaws in H\&C's survey and article. Table 2 summarizes the key studies we included that provide contradictory information to, and evidence disputing, the arguments used by $\mathrm{H} \& \mathrm{C}$ in their ar- 
ticle. Most of the claims made about MC and its sequelae are consistently contradicted by strong scientific evidence that $\mathrm{H} \& \mathrm{C}$ ignore. This leads us to dismiss the findings as mostly the unreliable opinions of MC opponents who have been indoctrinated into belief in the fallacies perpetrated by cognate anti-MC organizations on the Internet. We find the premise of the study to be an example of the post hoc ergo propter hoc (Latin: "after this, therefore because of this") informal fallacy (often shortened simply to post hoc fallacy) that states "Since event $Y$ followed event $X$, event $Y$ must have been caused by event $X$." The survey and its uncritical presentation do a disservice to evidence-based medicine, sexual health, mental health, public health, human rights, and pediatric policy development. As well as adversely affecting psychologically vulnerable men, anti-MC propaganda may also mislead such men into thinking that symptoms they may be experiencing are due to their circumcision when, in fact, their symptoms are due to medical or psychological problems. Consequently, as well as suffering undue anxiety, those men may not address the real cause of their problem, whatever it may be, blaming instead their circumcision. And men who need the procedure for medical reasons may be deterred from consulting with a medical practitioner, thereby unnecessarily prolonging, or exacerbating, their problem.

The ancient Greek philosopher, Epictetus, espoused what is today recognized as the fundamental principle of cognitive-behavioural psychology: It is not so much what happens to a person that matters, but their view of it! Sometimes referred as the A-B-C model, where A is the activating event, B is the belief about the event, and $\mathrm{C}$ is the emotional and behavioural consequent of the belief. For example, delayed ejaculation can occur in both circumcised and uncircumcised men. Let us assume, for the moment, that, ceteris paribus, delayed ejaculation is caused by neonatal circumcision. That could be viewed as an awful, dysfunctional condition. Yet others might view it as a benefit, in that there is more time to enjoy intercourse. The first person would be unhappy, perhaps even angry; the second person would be thrilled. Some "problems" are only problems because they are construed as such.

Once men have been persuaded that their newborn circumcision is a problem, other psychological processes come into play-for example, confirmation bias: seeking and accepting only that which agrees with one's established belief, and rejection of that which disagrees. This sums up the essence of H\&C's article.

\section{Conflicts of Interest}

Stephen Moreton is an editor of, and regular contributor to, CircFacts (http://www.circfacts.org), a website that critically examines arguments opposing male circumcision. Brian Morris is a member of the Circumcision Academy of Australia, a not-for-profit, government registered, medical society that provides evidence-based information on male circumcision to parents, practitioners and others, as well as contact details of doctors who perform the procedure. The authors have no financial, religious or other affiliations that might influence the topic of MC. 


\section{References}

[1] Cox, G. and Morris, B.J. (2012) Why Circumcision: From Pre-History to the Twenty-First Century. In: Bolnick, D.A., Koyle, M.A. and Yosha, A., Eds., Surgical Guide to Circumcision, Springer, London, Chapter 21, 243-259.

https://doi.org/10.1007/978-1-4471-2858-8_21

https://www.researchgate.net/publication/278660669_Why_Circumcision_From_Pr ehistory_to_the_Twenty-First_Century

[2] Angulo, J.C. and Garcia-Diez, M. (2009) Male Genital Representation in Paleolithic Art: Erection and Circumcision before History. Urology, 74, 10-14. https://doi.org/10.1016/j.urology.2009.01.010

[3] Morris, B.J., Wamai, R.G., Henebeng, E.B., et al. (2016) Estimation of Country-Specific and Global Prevalence of Male Circumcision. Population Health $\mathrm{Me}$ trics, 14, Article 4. https://doi.org/10.1186/s12963-016-0073-5

[4] Morris, B.J., Wamai, R.G., Henebeng, E.B., et al. (2016) Erratum to: Estimation of Country-Specific and Global Prevalence of Male Circumcision. Population Health Metrics, 14, Article 11. https://doi.org/10.1186/s12963-016-0080-6

[5] Cox, G. (1995) De Virginibus, Puerisque. The Function of the Human Foreskin Considered from an Evolutionary Perspective. Medical Hypotheses, 45, 617-621. https://doi.org/10.1016/0306-9877(95)90248-1

[6] Introcaso, C.E., Xu, F., Kilmarx, P.H., et al. (2013) Prevalence of Circumcision among Men and Boys Aged 14 to 59 Years in the United States, National Health and Nutrition Examination Surveys 2005-2010. Sexually Transmitted Diseases, 40, 521-525. https://doi.org/10.1097/01.OLQ.0000430797.56499.0d

[7] American Academy of Pediatrics Task Force on Circumcision (2012) Circumcision Policy Statement. Pediatrics, 130, 585-586. https://doi.org/10.1542/peds.2012-1989

[8] American Academy of Pediatrics Task Force on Circumcision (2012) Male Circumcision. Pediatrics, 130, e756-e785. https://doi.org/10.1542/peds.2012-1990

[9] Centers for Disease Control and Prevention (2018) Male Circumcision. https://www.cdc.gov/hiv/risk/male-circumcision.html

[10] El Bcheraoui, C., Zhang, X., Cooper, C.S., et al. (2014) Rates of Adverse Events Associated with Male Circumcision in US Medical Settings, 2001 to 2010. JAMA Pediatrics, 168, 625-634. https://doi.org/10.1001/jamapediatrics.2013.5414

[11] Morris, B.J., Moreton, S. and Krieger, J.N. (2019) Critical Evaluation of Arguments Opposing Male Circumcision: A Systematic Review. Journal of Evidence-Based Medicine, E-Pub Ahead of Final 8 Sep 2019. https://onlinelibrary.wiley.com/doi/10.1111/jebm.12361

[12] Hammond, T. and Carmack, A. (2017) Long-Term Adverse Outcomes from Neonatal Circumcision Reported in a Survey of 1,008 Men: An Overview of Health and Human Rights Implications. International Journal of Human Rights, 21, 189-218. https://doi.org/10.1080/13642987.2016.1260007

[13] Hammond, T. (2013) Survey Reveals Harm from Male Circumcision: Canadian Paediatric Society Alerted. Bonobo 3D. https://www.youtube.com/watch?v=IVUWXjYlbT8

[14] Hammond, T. (1999) A Preliminary Poll of Men Circumcised in Infancy or Childhood. BJU International, 83, 85-92. https://doi.org/10.1046/j.1464-410x.1999.0830s1085.x

[15] Hammond, T. (2013) Updating the CPS Neonatal Circumcision Policy Statement. http://circumcisionharm.org/CPS.pdf 
[16] Hutchinson, J. (1855) On the Influence of Circumcision in Preventing Syphilis. Medical Times and Gazette, 32, 542-543.

[17] Anonymous (1874) Circumcision. Edinburgh Medical Journal, 20, 282.

[18] Sayre, L.A. (1888) On the Deleterious Effects of a Narrow Prepuce and Preputial Adhesions. Transactions of the 9 th International Medical Congress, Vol. 3, 20. https://collections.nlm.nih.gov/ext/dw/101283080/PDF/101283080.pdf

[19] Hutchinson, J. (1890) A Plea for Circumcision. Archives of Surgery, 215.

[20] Freeland, E.H. (1900) Circumcision as a Preventative of Syphilis and Other Disorders. The Lancet, 156, 1869-1871. https://doi.org/10.1016/S0140-6736(01)82836-1

[21] Wolbarst, A.L. (1914) Universal Circumcision as a Sanitary Measure. JAMA, 62, 92-97. https://doi.org/10.1001/jama.1914.02560270008003

[22] Silby, F.A. (1913) Part II: Boys. In: Scharlieb, M. and Silby, F.A., Eds., Youth and Sex. Dangers and Safeguards for Girls and Boys, Dodge Publishing Co., London, 44-92.

[23] Rivin, B.E., Diekema, D.E., Mastroianni, A.C., et al. (2016) Critical Evaluation of Adler's Challenge to the CDC's Male Circumcision Recommendations. International Journal of Child Rights, 24, 265-303. https://doi.org/10.1163/15718182-02402004

[24] Morris, B.J., Krieger, J.N., Klausner, J.D. and Rivin, B.E. (2017) The Ethical Course Is to Recommend Infant Male Circumcision-Arguments Disparaging American Academy of Pediatrics Affirmative Policy Do Not Withstand Scrutiny. Journal of Law, Medicine \& Ethics, 45, 647-663. https://doi.org/10.1177/1073110517750603

[25] International NGO Council on Violence against Children (2012) Violating Children's Rights: Harmful Practices Based on Tradition, Culture, Religion or Superstition. https://resourcecentre.savethechildren.net/node/7212/pdf/7212.pdf

[26] Royal Dutch Medical Association (KNMG) (2010) Non-Therapeutic Circumcision of Male Minors. Royal Dutch Medical Association (KNMG), Utrecht. https://www.knmg.nl/circumcision/

[27] District Court, Cologne (2012) Landgericht Koln. 7 May 2012 Urteil 151 Ns 169/11.

[28] District Court of Cologne (2012) Judgement of 7 May 2012 on Male Circumcision for Religious Reasons. Durham University News. https://www.dur.ac.uk/ilm/news/?itemno=14984

[29] DW News-Service (2012) Circumcision Remains Legal in Germany. http://www.dw.de/circumcision-remains-legal-in-germany/a-16399336

[30] Stafford, N. (2012) German Ethics Council Backs Religious Circumcision If Specific Conditions Met. BMJ, 345, e5789. https://doi.org/10.1136/bmj.e5789

[31] Royal Courts of Justice (2015) Sir James Munby President of the Family Division. In the Matter of B and G (Children) (No. 2). https://www.judiciary.gov.uk/wp-content/uploads/2015/01/BandG_2_.pdf

[32] Morris, B.J., Bailis, S.A. and Wiswell, T.E. (2014) Circumcision Rates in the United States: Rising or Falling? What Effect Might the New Affirmative Pediatric Policy Statement Have? Mayo Clinic Proceedings, 89, 677-686. https://doi.org/10.1016/j.mayocp.2014.01.001

[33] Morris, B.J., Kennedy, S.E., Wodak, A.D., et al. (2017) Early Infant Male Circumcision: Systematic Review, Risk-Benefit Analysis, and Progress in Policy. World Journal of Clinical Pediatrics, 6, 89-102. https://doi.org/10.5409/wjcp.v6.i1.89

[34] Auvert, B., Taljaard, D., Lagarde, E., et al. (2005) Randomized, Controlled Intervention Trial of Male Circumcision for Reduction of HIV Infection Risk: The ANRS 
1265 Trial. PLoS Medicine, 2, e298. https://doi.org/10.1371/journal.pmed.0020298

[35] Bailey, R.C., Moses, S., Parker, C.B., et al. (2007) Male Circumcision for HIV Prevention in Young Men in Kisumu, Kenya: A Randomised Controlled Trial. The Lancet, 369, 643-656. https://doi.org/10.1016/S0140-6736(07)60312-2

[36] Gray, R.H., Kigozi, G., Serwadda, D., et al. (2007) Male Circumcision for HIV Prevention in Men in Rakai, Uganda: A Randomised Trial. The Lancet, 369, 657-666. https://doi.org/10.1016/S0140-6736(07)60313-4

[37] World Health Organization and UNAIDS (2007) New Data on Male Circumcision and HIV Prevention: Policy and Programme Implications.

http://who.int/hiv/mediacentre/MCrecommendations_en.pdf

[38] Weiss, H.A., Halperin, D., Bailey, R.C., et al. (2008) Male Circumcision for HIV Prevention: From Evidence to Action? AIDS, 22, 567-574. https://doi.org/10.1097/QAD.0b013e3282f3f406

[39] Siegfried, N., Muller, M., Deeks, J.J. and Volmink, J. (2009) Male Circumcision for Prevention of Heterosexual Acquisition of HIV in Men. Cochrane Database Systemetic Reviews, No. 2, CD003362. https://doi.org/10.1002/14651858.CD003362.pub2

[40] PEPFAR, U.S. President's Emergency Plan for AIDS Relief (2018) Fact Sheet. PEPFAR Latest Global Results. https://www.pepfar.gov/documents/organization/287811.pdf

[41] Fauci, A.S. and Eisinger, R.W. (2018) PEPFAR-15 Years and Counting the Lives Saved. New England Journal of Medicine, 378, 314-316. https://doi.org/10.1056/NEJMp1714773

[42] Hines, J.Z., Ntsuape, O.C., Malaba, K., et al. (2017) Scale-Up of Voluntary Medical Male Circumcision Services for HIV Prevention-12 Countries in Southern and Eastern Africa, 2013-2016. MMWR Morbidity and Mortality Weekly Report, 66, 1285-1290. https://doi.org/10.15585/mmwr.mm6647a2

[43] Tobian, A.A.R., Kacker, S. and Quinn, T.C. (2014) Male Circumcision: A Globally Relevant But Under-Utilized Method for the Prevention of HIV and Other Sexually Transmitted Infections. Annual Review of Medicine, 65, 293-306. https://doi.org/10.1146/annurev-med-092412-090539

[44] Benatar, M. and Benatar, D. (2003) Between Prophylaxis and Child Abuse: The Ethics of Neonatal Male Circumcision. American Journal of Bioethics, 3, 35-48. https://doi.org/10.1162/152651603766436216

[45] Benatar, D. and Benatar, M. (2003) How Not to Argue about Circumcision. American Journal of Bioethics, 3, W1-W9. https://doi.org/10.1162/152651603102387820

[46] Bates, M.J., Ziegler, J.B., Kennedy, S.E., et al. (2013) Recommendation by a Law Body to Ban Infant Male Circumcision Has Serious Worldwide Implications for Pediatric Practice and Human Rights. BMC Pediatrics, 13, Article No. 136. https://doi.org/10.1186/1471-2431-13-136

[47] Benatar, D. (2013) Evaluations of Circumcision Should Be Circumscribed by the Evidence. Journal of Medical Ethics, 39, 431-432. https://doi.org/10.1136/medethics-2013-101519

[48] Jacobs, A.J. (2013) The Ethics of Circumcision of Male Infants. Israel Medical Association Journal, 15, 60-65.

[49] Jacobs, A.J. and Arora, K.S. (2015) Ritual Male Infant Circumcision and Human Rights. American Journal of Bioethics, 15, 30-39. https://doi.org/10.1080/15265161.2014.990162

[50] Bester, J.C. (2015) Ritual Male Infant Circumcision: The Consequences and the 
Principles Say Yes. American Journal of Bioethics, 15, 56-58. https://doi.org/10.1080/15265161.2014.990164

[51] Moreton, S. (2012) Sabotage Studies. Screenshots from "The WHOLE Network". CircFacts.org. Real Facts about Male Circumcision.

http://circfacts.org/cyber-bullying/\#cyber13

[52] Bossio, J.A., Pukall, C.F. and Bartley, K. (2015) You Either Have It or You Don't: The Impact of Male Circumcision Status on Sexual Partners. Canadian Journal of Human Sexuality, 24, 104-119. https://doi.org/10.3138/cjhs.242-A2

[53] Bossio, J.A., Pukall, C.F. and Steele, S.S. (2016) Examining Penile Sensitivity in Neonatally Circumcised and Intact Men Using Quantitative Sensory Testing. Journal of Urology, 195, 1848-1853. https://doi.org/10.1016/j.juro.2015.12.080

[54] Stern, M.J. (2013) How Circumcision Broke the Internet. Slate. https://slate.com/technology/2013/09/intactivists-online-a-fringe-group-turned-the -internet-against-circumcision.html

[55] Task Force on Circumcision (2013) Cultural Bias and Circumcision: The AAP Task Force on Circumcision Responds. Pediatrics, 131, 801-804. https://doi.org/10.1542/peds.2013-0081

[56] Morris, B.J., Tobian, A.A., Hankins, C.A., et al. (2014) Veracity and Rhetoric in Paediatric Medicine: A Critique of Svoboda and Van Howe's Response to the AAP Policy on Infant Male Circumcision. Journal of Medical Ethics, 40, 463-470. https://doi.org/10.1136/medethics-2013-101614

[57] Morris, B.J., Krieger, J.N. and Klausner, J.D. (2016) Critical Evaluation of Unscientific Arguments Disparaging Affirmative Infant Male Circumcision Policy. World Journal of Clinical Pediatrics, 5, 251-261. https://doi.org/10.5409/wjcp.v5.i3.251

[58] Morris, B.J. and Krieger, J.N. (2015) The Literature Supports Policies Promoting Neonatal Male Circumcision in North America. Journal of Sexual Medicine, 12, 1305. https://doi.org/10.1111/jsm.12855

[59] Centers for Disease Control and Prevention (2014) Recommendations for Providers Counseling Male Patients and Parents Regarding Male Circumcision and the Prevention of HIV Infection, STIs, and Other Health Outcomes. Federal Register, 79, 71433.

https://www.federalregister.gov/documents/2014/12/02/2014-27814/recommendati ons-for-providers-counseling-male-patients-and-parents-regarding-male-circumcis ion-and

[60] Centers for Disease Control and Prevention (2014) Division of HIV/AIDS Prevention, National Center for HIV/AIDS, Viral Hepatitis, STD, TB Prevention. Background, Methods, and Synthesis of Scientific Information Used to Inform the "Recommendations for Providers Counseling Male Patients and Parents Regarding Male Circumcision and the Prevention of HIV Infection, STIs, and Other Health Outcomes." http://arclaw.org/sites/default/files/CDC-2014-0012-0002.pdf

[61] Morris, B.J. and Krieger, J.N. (2013) Does Male Circumcision Affect Sexual Function, Sensitivity, or Satisfaction?-A Systematic Review. Journal of Sexual Medicine, 10, 2644-2657. https://doi.org/10.1111/jsm.12293

[62] Centers for Disease Control and Prevention (2018) Summary of Public Comments and CDC Responses to Public Comments for Information for Providers Counseling Male Patients and Parents Regarding Male Circumcision and the Prevention of HIV Infection, Sexually Transmitted Infections, and Other Health Outcomes. https://www.cdc.gov/hiv/pdf/risk/MC-HISA-Public-Comments-and-Responses.pdf

[63] Morris, B.J. (2015) Commentary: Do the Benefits of Male Circumcision Outweigh 
the Risks? A Critique of the Proposed CDC Guidelines. Frontiers in Pediatrics, 3, Article 88. https://doi.org/10.3389/fped.2015.00088

[64] Morris, B.J., Krieger, J.N. and Klausner, J.D. (2017) CDC’s Male Circumcision Recommendations Represent a Key Public Health Measure. Global Health, Science and Practice, 5, 15-27. https://doi.org/10.9745/GHSP-D-16-00390

[65] Morris, B.J., Waskett, J.H., Banerjee, J., et al. (2012) A “Snip" in Time: What Is the Best Age to Circumcise? BMC Pediatrics, 12, Article 20. https://doi.org/10.1186/1471-2431-12-20

[66] Bollinger, D. (2010) Lost Boys: An Estimate of U.S. Circumcision-Related Infant Deaths. Thymos. Journal of Boyhood Studies, 4, 78-90. https://doi.org/10.3149/thy.0401.78

[67] Morris, B.J., Bailey, R.C., Klausner, J.D., et al. (2012) Review: A Critical Evaluation of Arguments Opposing Male Circumcision for HIV Prevention in Developed Countries. AIDS Care, 24, 1565-1575. https://doi.org/10.1080/09540121.2012.661836

[68] Elhaik, E. (2019) Neonatal Circumcision and Prematurity Are Associated with Sudden Infant Death Syndrome (SIDS). Journal of Clinical and Translational Research, 4, 136-151. https://doi.org/10.18053/jctres.04.201802.005

[69] Earp, B.D., Allareddy, V., Allareddy, V. and Rotta, A.T. (2018) Factors Associated with Early Deaths Following Neonatal Male Circumcision in the United States, 2001 to 2010. Clinical Pediatrics (Philadelphia), 57, 1532-1540. https://doi.org/10.1177/0009922818790060

[70] Kigozi, G., Watya, S., Polis, C.B., et al. (2008) The Effect of Male Circumcision on Sexual Satisfaction and Function, Results from a Randomized Trial of Male Circumcision for Human Immunodeficiency Virus Prevention, Rakai, Uganda. BJU International, 101, 65-70. https://doi.org/10.1111/j.1464-410X.2007.07369.x

[71] Krieger, J.N., Mehta, S.D., Bailey, R.C., et al. (2008) Adult Male Circumcision: Effects on Sexual Function and Sexual Satisfaction in Kisumu, Kenya. Journal of Sexual Medicine, 5, 2610-2622. https://doi.org/10.1111/j.1743-6109.2008.00979.x

[72] Tian, Y., Liu, W., Wang, J.Z., et al. (2013) Effects of Circumcision on Male Sexual Functions: A Systematic Review and Meta-Analysis. Asian Journal of Andrology, 15, 662-666. https://doi.org/10.1038/aja.2013.47

[73] Yang, Y., Wang, X., Bai, Y. and Han, P. (2018) Circumcision Does Not Have Effect on Premature Ejaculation: A Systematic Review and Meta-Analysis. Andrologia, 50, e12851. https://doi.org/10.1111/and.12851

[74] Shabanzadeh, D.M., Düring, S. and Frimont-Moller, C. (2016) Male Circumcision Does Not Result in Inferior Perceived Male Sexual Function-A Systematic Review. Danish Medical Journal, 63, A5245.

[75] Homfray, V., Tanton, C., Mitchell, K.R., et al. (2015) Examining the Association between Male Circumcision and Sexual Function: Evidence from a British Probability Survey. AIDS, 29, 1411-1416. https://doi.org/10.1097/QAD.0000000000000745

[76] Cox, G., Krieger, J.N. and Morris, B.J. (2015) Histological Correlates of Penile Sexual Sensation: Does Circumcision Make a Difference? Sexual Medicine, 3, 76-85. https://doi.org/10.1002/sm2.67

[77] YouGov (2015) Circumcision Survey. http://cdn.yougov.com/cumulus_uploads/document/ugf8jh0ufk/toplines_OPI_circ umcision_20150202.pdf

[78] YouGov (2018) Panel Methodology. 
https://yougov.co.uk/about/panel-methodology

[79] Schober, J.M., Meyer-Bahlburg, H.F. and Dolezal, C. (2009) Self-Ratings of Genital Anatomy, Sexual Sensitivity and Function in Men Using the "Self-Assessment of Genital Anatomy and Sexual Function, Male" Questionnaire. BJU International, 103, 1096-1103. https://doi.org/10.1111/j.1464-410X.2008.08166.x

[80] Halata, Z. and Munger, B.L. (1986) The Neuroanatomical Basis for the Protopathic Sensibility of the Human Glans Penis. Brain Research, 371, 205-230. https://doi.org/10.1016/0006-8993(86)90357-4

[81] Szasz, G. and Carpenter, C. (1989) Clinical Observations in Vibratory Stimulation of the Penis of Men with Spinal Cord Injury. Archives of Sexual Behavior, 18, 461-474. https://doi.org/10.1007/BF01541673

[82] Sarkarati, M., Rossier, A.B. and Fam, B.A. (1987) Experience in Vibratory and Electro-Ejaculation Techniques in Spinal Cord Injury Patients: A Preliminary Report. Journal of Urology, 138, 59-62. https://doi.org/10.1016/S0022-5347(17)42988-0

[83] Kigozi, G., Wawer, M., Ssettuba, A., et al. (2009) Foreskin Surface Area and HIV Acquisition in Rakai, Uganda (Size Matters). AIDS, 23, 2209-2213. https://doi.org/10.1097/QAD.0b013e328330eda8

[84] Darwin, C. (1859) The Origin of Species by Means of Natural Selection. John Murray, London.

[85] Moreton, S. (2019) Circumcision Removes Half the Penile Skin. Circfacts.org. Real Facts about Male Circumcision.

http://circfacts.org/function-sensation/\#sens12

[86] Moreton, S. (2019) Circumcision Removes Half the Skin of the Penis. CircFacts.org. Real Facts about Male Circumcision. http://circfacts.org/function-sensation/\#sens12

[87] Wamai, R.G., Morris, B.J., Waskett, J.H., et al. (2012) Criticisms of African Trials Fail to Withstand Scrutiny: Male Circumcision Does Prevent HIV Infection. Journal of Law and Medicine, 20, 93-123.

[88] de Witte, L., Nabatov, A., Pion, M., et al. (2007) Langerin Is a Natural Barrier to HIV-1 Transmission by Langerhans Cells. Nature Medicine, 13, 367-371. https://doi.org/10.1038/nm1541

[89] Schwartz, O. (2007) Langerhans Cells Lap up HIV-1. Nature Medicine, 13, 245-246. https://doi.org/10.1038/nm0307-245

[90] Morris, B.J. and Wamai, R.G. (2012) Biological Basis for the Protective Effect Conferred by Male Circumcision against HIV Infection. International Journal of STD \&AIDS, 23, 153-159. https://doi.org/10.1258/ijsa.2011.011228

[91] Moreton, S. (2019) The Foreskin Has Immunological Functions. CircFacts.org. Real Facts about Male Circumcision. http://circfacts.org/function-sensation/\#sens13

[92] Wei, C., Raymond, H.F., McFarland, W., et al. (2011) What Is the Potential Impact of Adult Circumcision on the HIV Epidemic among Men Who Have Sex with Men in San Francisco? Sexually Transmitted Diseases, 38, 353-355. https://doi.org/10.1097/OLQ.0b013e3181fe6523

[93] Westercamp, N. and Bailey, R.C. (2007) Acceptability of Male Circumcision for Prevention of HIV/AIDS in Sub-Saharan Africa: A Review. AIDS and Behavior, 11, 341-355. https://doi.org/10.1007/s10461-006-9169-4

[94] Gasasira, R.A., Sarker, M., Tsague, L., et al. (2012) Determinants of Circumcision and Willingness to Be Circumcised by Rwandan Men, 2010. BMC Public Health, 
12, 134. https://doi.org/10.1186/1471-2458-12-134

[95] Peltzer, K., Onoya, D., Makonko, E. and Simbayi, L. (2014) Prevalence and Acceptability of Male Circumcision in South Africa. African Journal of Traditional, Complementary, and Alternative Medicines, 11, 126-130. https://doi.org/10.4314/ajtcam.v11i4.19

[96] Moreton, S. (2017) Men Rarely Choose to Be Circumcised. Circfacts.org. Real Facts about Male Circumcision. http://circfacts.org/general-information/\#med4

[97] MacLaren, D., Tommbe, R., Mafile'o, T., et al. (2013) Foreskin Cutting Beliefs and Practices and the Acceptability of Male Circumcision for HIV Prevention in Papua New Guinea. BMC Public Health, 13, 818. https://doi.org/10.1186/1471-2458-13-818

[98] Huang, J., Jiang, J., Abdullah, A.S., et al. (2013) Factors Associated with Acceptability of Circumcision among Male Drug Users in Western China: A Cross-Sectional Study. International Journal of STD \& AIDS, 24, 541-547. https://doi.org/10.1177/0956462412473893

[99] Jiang, J., Huang, J., Yang, X., et al. (2013) Acceptance of Male Circumcision among Male Rural-to-Urban Migrants in Western China. AIDS Research and Human Retroviruses, 29, 1582-1588. https://doi.org/10.1089/aid.2013.0156

[100] Wang, Z., Feng, T., Lau, J.T. and Kim, Y. (2016) Acceptability of Voluntary Medical Male Circumcision (VMMC) among Male Sexually Transmitted Diseases Patients (MSTDP) in China. PLoS ONE, 11, e0149801. https://doi.org/10.1371/journal.pone.0149801

[101] Jiang, J., Su, J., Yang, X., et al. (2015) Acceptability of Male Circumcision among College Students in Medical Universities in Western China: A Cross-Sectional Study. PLoS ONE, 10, e0135706. https://doi.org/10.1371/journal.pone.0135706

[102] Figueroa, J.P. and Cooper, C.J. (2010) Attitudes towards Male Circumcision among Attendees at a Sexually Transmitted Infection Clinic in Kingston, Jamaica. West Indian Medical Journal, 59, 351-355.

[103] Hudson, F.P., Miller, W.C., Rao, S., et al. (2018) Prevalence and Predictors of Uncircumcised, Kenyan Men's Desire for Circumcision for Their Infant Sons. AIDS and Behavior, 22, 471-478. https://doi.org/10.1007/s10461-017-1681-1

[104] Grund, J.M., Bryant, T.S., Toledo, C., et al. (2019) Association of Male Circumcision with Women's Knowledge of Its Biomedical Effects and with Their Sexual Satisfaction and Function: A Systematic Review. AIDS and Behavior, 23, 1104-1114. https://doi.org/10.1007/s10461-018-2313-0

[105] Morris, B.J., Hankins, C.A., Lumbers, E.R., et al. (2019) Sex and Male Circumcision: Women's Preferences across Different Cultures and Countries: A Systematic Review. Sexual Medicine, 7, 145-161. https://doi.org/10.1016/j.esxm.2019.03.003

[106] Wiswell, T.E. and Geschke, D.W. (1989) Risks from Circumcision during the First Month of Life Compared with Those for Uncircumcised Boys. Pediatrics, 83, 1011-1015.

[107] Ben Chaim, J., Livne, P.M., Binyamini, J., et al. (2005) Complications of Circumcision in Israel: A One Year Multicenter Survey. Israel Medical Association Journal, 7, 368-370.

[108] Moreton, S. (2016) Gliding along. Circfacts.org. Real Facts about Male Circumcision. http://circfacts.org/function-sensation/\#sens4

[109] CircumcisionChoice (2017) The 16 Foreskin Functions-A Critical Analysis. CircumcisionCoice.com. 
https://www.circumcisionchoice.com/single-post/16Functions

[110] Nordstrom, M.P., Westercamp, N., Jaoko, W., et al. (2017) Medical Male Circumcision Is Associated with Improvements in Pain during Intercourse and Sexual Satisfaction in Kenya. Journal of Sexual Medicine, 14, 601-612. https://doi.org/10.1016/j.jsxm.2017.02.014

[111] Chmel, R., Novackova, M., Fait, T., et al. (2019) Clitoral Phimosis: Effects on Female Sexual Function and Surgical Treatment Outcomes. Journal of Sexual Medicine, 16, 257-266. https://doi.org/10.1016/j.jsxm.2018.12.012

[112] McDonald, C.F. (1958) Circumcision of the Female. GP, 18, 98-99. https://doi.org/10.1353/frc.1958.0004

[113] Rathmann, W.G. (1959) Female Circumcision, Indications and a New Technique. $G P, 20,115-120$.

[114] Hodgkinson, D.J. and Hait, G. (1984) Aesthetic Vaginal Labioplasty. Plastic and Reconstructive Surgery, 74, 414-416. https://doi.org/10.1097/00006534-198409000-00015

[115] Dobbeleir, J.M., Landuyt, K.V. and Monstrey, S.J. (2011) Aesthetic Surgery of the Female Genitalia. Seminars in Plastic Surgery, 25,130-141. https://doi.org/10.1055/s-0031-1281482

[116] Morris, B.J. and Krieger, J.N. (2017) Does Circumcision Increase Meatal Stenosis Risk?-A Systematic Review and Meta-Analysis. Urology, 110, 16-26. https://doi.org/10.1016/j.urology.2017.07.027

[117] Morris, B.J. and Krieger, J.N. (2018) Re: Cultural Background, Non-Therapeutic Circumcision and the Risk of Meatal Stenosis and Other Urethral Stricture Disease: Two Nationwide Register-Based Cohort Studies in Denmark 1977-2013. Surgeon, 16, 126-129. https://doi.org/10.1016/j.surge.2017.08.001

[118] Moreton, S. (2017) Lying. Circfacts.org. Real Facts about Male Circumcision. http://circfacts.org/cyber-bullying/\#cyber10

[119] Sorrells, M.L., Snyder, J.L., Reiss, M.D., et al. (2007) Fine-Touch Pressure Thresholds in the Adult Penis. BJU International, 99, 864-869. https://doi.org/10.1111/j.1464-410X.2006.06685.x

[120] Waskett, J.H. and Morris, B.J. (2007) Fine-Touch Pressure Thresholds in the Adult Penis. BJU International, 99, 1551-1552. https://doi.org/10.1111/j.1464-410X.2007.06970_6.x

[121] Moreton, S. (2016) “10,000, 20,000, 70,000 Nerve Endings”: A Myth That Keeps on Growing. Circfacts.org. Real Facts about Male Circumcision. http://circfacts.org/function-sensation/\#sens1

[122] Richters, J., Gerofi, J. and Donovan, B. (1995) Are Condoms the Right Size(s)? A Method for Self-Measurement of the Erect Penis. Venereology, 8, 77-81.

[123] Park, J.K., Doo, A.R., Kim, J.H., et al. (2016) Prospective Investigation of Penile Length with Newborn Male Circumcision and Second to Fourth Digit Ratio. Canadian Urological Association Journal, 10, E296-E299. https://doi.org/10.5489/cuaj.3590

[124] Frisch, M. and Simonsen, J. (2018) Cultural Background, Non-Therapeutic Circumcision and the Risk of Meatal Stenosis and Other Urethral Stricture Disease: Two Nationwide Register-Based Cohort Studies in Denmark 1977-2013. Surgeon, 16, 107-118. https://doi.org/10.1016/j.surge.2016.11.002

[125] Payne, K., Thaler, L., Kukkonen, T., et al. (2007) Sensation and Sexual Arousal in Circumcised and Uncircumcised Men. Journal of Sexual Medicine, 4, 667-674. 
https://doi.org/10.1111/j.1743-6109.2007.00471.x

[126] Bleustein, C.B., Fogarty, J.D., Eckholdt, H., et al. (2005) Effect of Neonatal Circumcision on Penile Neurological Sensation. Urology, 65, 773-777.

https://doi.org/10.1016/j.urology.2004.11.007

[127] Rhodin, J.A.G. (1974) Histology. A Text and Atlas. Oxford University Press, London, $893 \mathrm{p}$.

[128] Winkelmann, R.K. (1956) The Cutaneous Innervation of Human Newborn Prepuce. Journal ofInvestigative Dermatology, 26, 53-67. https://doi.org/10.1038/jid.1956.5

[129] Yang, C.C. and Bradley, W.E. (1998) Peripheral Distribution of the Human Dorsal Nerve of the Penis. Journal of Urology, 159, 1912-1916. https://doi.org/10.1016/S0022-5347(01)63194-X

[130] Podnar, S. (2012) Clinical Elicitation of the Penilo-Cavernosus Reflex in Circumcised Men. BJU International, 109, 582-585. https://doi.org/10.1111/j.1464-410X.2011.10364.x

[131] Blaivas, J.G., Zayed, A.A. and Labib, K.B. (1981) The Bulbocavernosus Reflex in Urology: A Prospective Study of 299 Patients. Journal of Urology, 126, 197-199. https://doi.org/10.1016/S0022-5347(17)54445-6

[132] Taddio, A., Goldbach, M., Ipp, M., et al. (1995) Effect of Neonatal Circumcision on Pain Responses during Vaccination in Boys. The Lancet, 345, 291-292. https://doi.org/10.1016/S0140-6736(95)90278-3

[133] Taddio, A., Katz, J., Ilersich, A.L. and Koren, G. (1997) Effect of Neonatal Circumcision on Pain Response during Subsequent Routine Vaccination. The Lancet, 349, 599-603. https://doi.org/10.1016/S0140-6736(96)10316-0

[134] Szabo, R. and Short, R.V. (2000) How Does Male Circumcision Protect against HIV Infection? BMJ, 320, 1592-1594. https://doi.org/10.1136/bmj.320.7249.1592

[135] Moreton, S. (2016) Keratinization. Circfacts.org. Real Facts about Male Circumcision. http://circfacts.org/function-sensation/\#sens3

[136] Jack in the World (1997) Jackinworld Survey \#2 Results. http://old.jackinworld.com/library/surveys/survey2.html

[137] Frisch, M., Lindholm, M. and Gronbaek, M. (2011) Male Circumcision and Sexual Function in Men and Women: A Survey-Based, Cross-Sectional Study in Denmark. International Journal of Epidemiology, 40, 1367-1381.

https://doi.org/10.1093/ije/dyr104

[138] Morris, B.J., Waskett, J.H. and Gray, R.H. (2012) Does Sexual Function Survey in Denmark Offer Any Support for Male Circumcision Having an Adverse Effect? International Journal of Epidemiology, 41, 310-312. https://doi.org/10.1093/ije/dyr180

[139] Meyrowitsch, D. (2019) The Myth of Male Circumcision and Sexual Dysfunction The Guardian.

https://www.theguardian.com/society/2019/jul/24/the-myth-of-male-circumcisionand-sexual-dysfunction

[140] Murray, J. (2011) Male Circumcison. Interview of Dr Morten Frisch and Professor Michael King. Woman's Hour (Podcast), BBC Radio 4. http://www.bbc.co.uk/programmes/b011zzh8

[141] Frisch, M. (2013) Circumcision and Sexual Function Difficulties. Bonobo 3D. https://www.youtube.com/watch?v=yfGkZZ-KzpU

[142] Fergusson, D.M., Lawton, J.M. and Shannon, F.T. (1988) Neonatal Circumcision and Penile Problems: An 8-Year Longitudinal Study. Pediatrics, 81, 537-541. 
[143] Fergusson, D.M., Boden, J.M. and Horwood, L.J. (2008) Neonatal Circumcision: Effects on Breastfeeding and Outcomes Associated with Breastfeeding. Journal of Paediatrics and Child Health, 44, 44-49.

[144] Moreton, S. (2019) Circumcision Causes Psychological Damage. Circfacts.org. Real Facts about Male Circumcision. http://circfacts.org/medical-benefits/risks-complications/\#risk6

[145] Morris, B.J. and Waskett, J.H. (2012) Claims That Circumcision Increases Alexithymia and Erectile Dysfunction Are Unfounded: A Critique of Bollinger and Van Howe's "Alexithymia and Circumcision Trauma: A Preliminary Investigation". International Journal of Men's Health, 11, 177-181. https://doi.org/10.3149/jmh.1102.177

[146] Mohl, P.C., Adams, R., Greer, D.M. and Sheley, K.A. (1981) Prepuce Restoration Seekers: Psychiatric Aspects. Archives of Sexual Behavior, 10, 383-393. https://doi.org/10.1007/BF01565542

[147] Fenwick, A.S. and Sullivan, K.A. (2011) Potential Link between Body Dysmorphic Disorder Symptoms and Alexithymia in an Eating-Disordered Treatment-Seeking Sample. Psychiatry Research, 189, 299-304.

https://doi.org/10.1016/j.psychres.2011.07.011

[148] Taylor, G.J., Bagby, R.M. and Parker, J.D.A. (1997) Disorders of Affect Regulation: Alexithymia in Medical and Psychiatric Illness. Cambridge University Press, Cambridge. https://doi.org/10.1017/CBO9780511526831

[149] Rescorla, L.A., Achenbach, T.M., Ivanova, M.Y., et al. (2011) International Comparisons of Behavioral and Emotional Problems in Preschool Children: Parents' Reports from 24 Societies. Journal of Clinical Child \& Adolescent Psychology, 40, 456-467. https://doi.org/10.1080/15374416.2011.563472

[150] Rescorla, L., Achenbach, T.M., Ivanova, M.Y., et al. (2007) Behavioral and Emotional Problems Reported by Parents of Children Ages 6 to 16 in 31 Societies. Journal of Emotional and Behavioral Disorders, 15, 130-142. https://doi.org/10.1177/10634266070150030101

[151] Mason, O., Tyson, M., Jones, C. and Potts, S. (2005) Alexithymia: Its Prevalence and Correlates in a British Undergraduate Sample. Psychology and Psychotherapy, 78, 113-125. https://doi.org/10.1348/147608304X21374

[152] Bollinger, D. and Van Howe, R. (2012) Preliminary Results Are Preliminary, Not "Unfounded": Reply to Morris and Waskett. International Journal of Men's Health, 11, 181-184.

[153] Circumcision Choice (2019) Intactivism Is a Mental Disorder. CircumcisionChoice.com. https://www.circumcisionchoice.com/single-post/MentalDisorder

[154] Laumann, E.O., Masi, C.M. and Zuckerman, E.W. (1997) Circumcision in the United States. Prevalence, Prophyactic Effects, and Sexual Practice. Journal of the American Medical Association, 277, 1052-1057. https://doi.org/10.1001/jama.1997.03540370042034

[155] Crosby, R. and Charnigo, R.J. (2013) A Comparison of Condom Use Perceptions and Behaviours between Circumcised and Intact Men Attending Sexually Transmitted Disease Clinics in the United States. International Journal of STD \& AIDS, 24, 175-178. https://doi.org/10.1177/0956462412472444

[156] Crosby, R.A., Graham, C.A., Mena, L., et al. (2016) Circumcision Status Is Not Associated with Condom Use and Prevalence of Sexually Transmitted Infections among Young Black MSM. AIDS and Behavior, 20, 2538-2542.

https://doi.org/10.1007/s10461-015-1212-x 
[157] Moreton, S. (2017) Risk Compensation-An Intactivist Half-Truth. CircFacts.org. Real Facts about Male Circumcision. http://circfacts.org/medical-benefits/hivaids/\#hiv3

[158] American Psychiatric Association (2013) Diagnostic \& Statistical Manual 5th Revision (DSM-5). http://www.dsm5.org/Pages/Default.aspx

[159] Kafka, M.P. (2010) The DSM Diagnostic Criteria for Paraphilia Not Otherwise Specified. Archives of Sexual Behavior, 39, 373-376. https://doi.org/10.1007/s10508-009-9552-0

[160] Schultheiss, D., Truss, M.C., Stief, C.G. and Jonas, U. (1998) Uncircumcision: A Historical Review of Preputial Restoration. Plastic and Reconstructive Surgery, 101, 1990-1998. https://doi.org/10.1097/00006534-199806000-00037

[161] Yahoo Questions (2015) Should I Get Re-Circumcised after 20 Years and Restoring Improperly? Yahoo.com. https://answers.yahoo.com/question/index?qid=20100401174412AARIqlC

[162] Walter, G. and Streimer, J. (1990) Genital Self-Mutilation: Attempted Foreskin Reconstruction. British Journal of Psychiatry, 156, 125-127. https://doi.org/10.1192/bjp.156.1.125

[163] Hoffman, B.L., Felter, E.M., Chu, K.H., et al. (2019) It's Not All about Autism: The Emerging Landscape of Anti-Vaccination Sentiment on Facebook. Vaccine, 37, 2216-2223. https://doi.org/10.1016/j.vaccine.2019.03.003

[164] Anonymous (2019) Anti-Abortion Violence. Wikipedia. https://en.wikipedia.org/wiki/Anti-abortion_violence

[165] Circumcision Choice (2018) How Should Intactivists Respond If One of Their Own Bombs a Hospital. CircumcisionChoce.com. https://www.circumcisionchoice.com/single-post/McVeigh

[166] NeonatalCutting.org (2019) Listings. http://neonatalcutting.org/listings

[167] Williams, N. and Kapila, L. (1993) Complications of Circumcision. British Journal of Surgery, 80, 1231-1236. https://doi.org/10.1002/bjs.1800801005

[168] Hung, Y.C., Chang, D.C., Westfal, M.L., et al. (2019) A Longitudinal Population Analysis of Cumulative Risks of Circumcision. Journal of Surgical Research, 233, 111-117. https://doi.org/10.1016/j.jss.2018.07.069

[169] Darby, R. (2015) Risks, Benefits, Complications and Harms: Neglected Factors in the Current Debate on Non-Therapeutic Circumcision. Kennedy Institute of Ethics Journal, 25, 1-34. https://doi.org/10.1353/ken.2015.0004

[170] Immerman, R.S. and Mackey, W.C. (1998) A Proposed Relationship between Circumcision and Neural Reorganization. Journal of Genetic Psychology, 159, 367-378. https://doi.org/10.1080/00221329809596158

[171] Ullmann, E., Licinio, J., Barthel, A., et al. (2017) Circumcision Does Not Alter Long-Term Glucocorticoids Accumulation or Psychological Effects Associated with Trauma- and Stressor-Related Disorders. Translational Psychiatry, 7, e1063. https://doi.org/10.1038/tp.2017.23

[172] Calnan, M., Douglas, J.W.B. and Goldstein, H. (1978) Tonsillectomy and Circumcision: Comparison of Two Cohorts. International Journal of Epidemiology, 7, 79-85. https://doi.org/10.1093/ije/7.1.79

[173] Stenram, A., Malmfors, G. and Okmian, L. (1986) Circumcision for Phimosis-Indications and Results. Acta Paediatrica Scandinavica, 75, 321-323. https://doi.org/10.1111/j.1651-2227.1986.tb10207.x

[174] Stenram, A., Malmfors, G. and Okmian, L. (1986) Circumcision for Phimosis: A 
Follow-Up Study. Scandinavian Journal of Urology and Nephrology, 20, 89-92. https://doi.org/10.3109/00365598609040554

[175] Tinari, P.D. (2009) MRI Studies: The Brain Permanently Altered from Infant Circumcision. Peaceful Parenting. http://www.drmomma.org/2009/10/mri-studies-brain-permanently-altered.html

[176] Schaab, M.L. (2017) MRI Scans and Circumcision Brain Damage. The Lie That Just Won't Die. http://circfacts.org/debunking-corner/\#debk4

[177] Marshall, R.E., Porter, F.L., Rogers, A.G., et al. (1982) Circumcision: II. Effects upon Mother-Infant Interaction. Early Human Development, 7, 367-374. https://doi.org/10.1016/0378-3782(82)90038-X

[178] United Nations Human Rights Office of the High Commissioner for Human Rights (1989) Convention on the Rights of the Child. 44/25 20 November 1989. http://www.ohchr.org/en/professionalinterest/pages/crc.aspx

[179] Clark, P.A., Eisenman, J. and Szapor, S. (2007) Mandatory Neonatal Male Circumcision in Sub-Saharan Africa: Medical and Ethical Analysis. Medical Science Monitor, 13, RA205-RA213.

[180] Mazor, J. (2013) The Child's Interests and the Case for the Permissibility of Male Infant Circumcision. Journal of Medical Ethics, 39, 421-428. https://doi.org/10.1136/medethics-2013-101318

[181] Brusa, M. and Barilan, Y.M. (2009) Cultural Circumcision in EU Public Hospitals-An Ethical Discussion. Bioethics, 23, 470-482.

https://doi.org/10.1111/j.1467-8519.2008.00683.x

[182] Adler, P.W. (2016) The Draft CDC Circumcision Recommendations: Medical, Ethical, Legal, and Procedural Concerns. International Journal of Children's Rights, 24, 237-262. https://doi.org/10.1163/15718182-02402001

[183] Svoboda, J.S., Adler, P.W. and Van Howe, R.S. (2016) Circumcision Is Unethical and Unlawful. Journal of Law, Medicine \& Ethics, 44, 263-282. https://doi.org/10.1177/1073110516654120

[184] Centers for Disease Control and Prevention (2014) Recommendations for Providers Counseling Male Patients and Parents Regarding Male Circumcision and the Prevention of HIV Infection, STIs, and Other Health Outcomes. Docket No. CDC-2014-0012-0002.

http://www.regulations.gov/\#!documentDetail;D=CDC-2014-0012-0002

[185] Svoboda, J.S. and Van Howe, R.S. (2013) Out of Step: Fatal Flaws in the Latest AAP Policy Report on Neonatal Circumcision. Journal of Medical Ethics, 39, 434-441. https://doi.org/10.1136/medethics-2013-101346

[186] Earp, B.D. (2015) Do the Benefits of Male Circumcision Outweigh the Risks? A Critique of the Proposed CDC Guidelines. Frontiers in Pediatrics, 3, 18. https://doi.org/10.3389/fped.2015.00018

[187] Johns Hopkins University (2015) Hippocratic Oath, Modern Version. https://guides.library.jhu.edu/bioethics/codes

[188] Hammond, T. (2016) Global Survey of Circumcision Harm. http://www.circumcisionharm.org

[189] Hammond, T. (2011) Global Survey of Circumcision Harm. http://www.circumcisionharm.org/survey.htm

[190] Morris, B.J., Krieger, J.N. and Kigozi, G. (2013) Male Circumcision Decreases Penile Sensitivity as Measured in a Large Cohort. BJU International, 111, E269-E270. https://doi.org/10.1111/bju.12128_9 
[191] Bronselaer, G.A., Schober, J.M., Meyer-Bahlburg, H.F., et al. (2013) Male Circumcision Decreases Penile Sensitivity as Measured in a Large Cohort. BJU International, 111, 820-827. https://doi.org/10.1111/j.1464-410X.2012.11761.x

[192] Risser, J.M., Risser, W.L., Eissa, M.A., et al. (2004) Self-Assessment of Circumcision Status by Adolescents. Americal Journal of Epidemiology, 159, 1095-1097. https://doi.org/10.1093/aje/kwh149

[193] Yahoo Answers (2011) Should I Hate My Parents for Circumcising Me? https://answers.yahoo.com/question/index?qid=20110227140835AAsZGfE

[194] Bay Area Intactivists (2016) Incredibly Sad News: Jonathon Conte Has Taken His Own Life. http://www.bayareaintactivists.org/node/334

[195] Intaction (2017) In Memoriam Kevin Cagle. Young Man's Anguish over Circumcision Ends in Suicide. The Death of Kevin Cagle. http://intaction.org/kevin-cagle-circumcision-suicide

[196] Conte, J. (2016) Motivations of an Intactivist. http://intactnews.org/node/134/1318099689/jonathon-conte-motivations-intactivist

[197] Hammond, T. (1999) A Preliminary Poll of Men Circumcised in Infancy or Childhood. BJU International, 83, 85-92. https://www.ncbi.nlm.nih.gov/pubmed/?term=hammond+bju+int+1999

[198] Intact America (2014) Intactivist of the Month: Dr. Adrian Carmack. IntactAmerica.org. http://www.intactamerica.org/iotm_october2014

[199] Kabwama, S.N., Ssewanyana, D. and Berg-Beckhoff, G. (2018) The Association between Male Circumcision and Condom Use Behavior-A Meta-Analysis. Mater Sociomed, 30, 62-66. https://doi.org/10.5455/msm.2018.30.62-66 